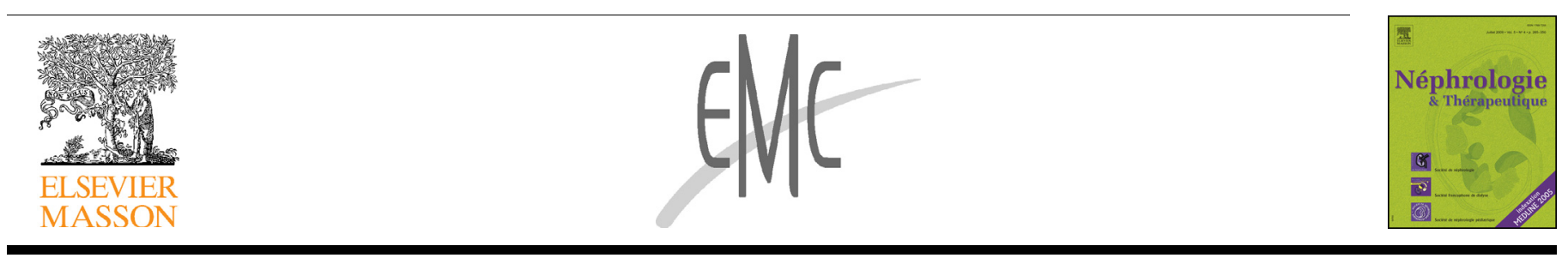

Expertise médicale continue en néphrologie

\title{
Exploration de la fonction glomérulaire rénale : estimation du débit de filtration glomérulaire
}

\author{
Exploration of renal glomerular function: estimation of glomerular filtration rate \\ Nicolas Maillard ${ }^{\mathrm{a}}$, Pierre Delanaye ${ }^{\mathrm{b}}$, Christophe Mariat ${ }^{\mathrm{a}, *}$ \\ a Service de néphrologie, Laboratoire d'explorations fonctionnelles rénales, Centre hospitalier universitaire de Saint-Étienne, Université Jean Monnet, \\ 42055 Saint-Étienne cedex 02, France \\ ${ }^{\mathrm{b}}$ Service de néphrologie, dialyse et transplantation, Centre hospitalier universitaire Sart Tilman, Université de Liège, Liège, Belgique
}

\section{N F O A R T I C L E}

\section{Mots clés :}

Débit de filtration glomérulaire

Équation MDRD

Cockcroft-Gault

Créatinine

Cystatine C

\begin{abstract}
R É S U M É
À côté des méthodes de mesure directe du débit de filtration glomérulaire, il existe de nombreuses formules ayant pour but d'estimer le débit de filtration glomérulaire à partir de marqueurs endogènes dont le plus utilisé est la créatinine sérique. Les dernières recommandations de la Haute Autorité de santé cautionnent sans ambiguité l'utilisation de l'équation CKD-EPI. L'évaluation du débit de filtration glomérulaire à partir de cette équation reste toutefois approximative dans de nombreuses situations où la concentration plasmatique de créatinine reflète mal le débit de filtration glomérulaire. Dans ces situations, la cystatine $C$ plasmatique pourrait être un marqueur endogène alternatif, potentiellement plus fiable que la créatinine plasmatique et ce d'autant plus qu'un standard de référence pour le dosage de la cystatine $C$ a été récemment développé. L'utilisation de la cystatine $C$ en pratique clinique commence à être évoquée mais nécessite encore d'être pleinement validée.
\end{abstract}

๑) 2015 Publié par Elsevier Masson SAS pour l'Association Société de néphrologie.
Keywords:

Glomerular filtration rate

MDRD equation

Cockcroft-Gault

Creatinin

Cystatin C

\begin{abstract}
A B S T R A C T
In addition to direct measurement methods of glomerular filtration rate, there are many formulas whose purpose is to estimate glomerular filtration rate from endogenous markers, of which the most used is serum creatinine. The latest recommendations the French health agency Haute Autorité de santé (HAS) unambiguously endorse the use of the CKD-EPI equation. The assessment of glomerular filtration rate from this equation however remains approximate in many situations where the plasma creatinine concentration poorly reflects the glomerular filtration rate. In these situations, plasma cystatin C could potentially be a more reliable alternative to endogenous plasma creatinine marker, especially since a reference standard for the determination of serum cystatin C concentration has recently been developed. Use of serum cystatin $C$ concentration in clinical practice begins to be mentioned, but still needs to be fully validated.
\end{abstract}

๑ 2015 Published by Elsevier Masson SAS on behalf of the Association Société de néphrologie.

\section{Introduction}

Cet article, consacré à l'exploration de la fonction glomérulaire se focalise sur l'estimation du débit de filtration glomérulaire (DFG). L'évaluation de la fonction rénale à partir des équations

\footnotetext{
4 Cet article est paru initialement dans EMC (Elsevier Masson SAS, Paris), Néphrologie 18-011-A-11, 2011. Nous remercions la rédaction d'EMC-Néphrologie pour son aimable autorisation de reproduction.

* Auteur correspondant.

Adresse e-mail : christophe.mariat@univ-st-etienne.fr (C. Mariat).
}

d'estimation du DFG reste un sujet très étudié et très débattu dans la littérature scientifique actuelle. Après avoir évoqué les différentes équations qui ont été successivement développées à partir de la créatinine sérique, nous discutons en détails les avantages et limites des trois estimateurs les plus utilisés : la formule de Cockcroft et Gault, l'équation modification of diet in renal disease (MDRD) et l'équation proposée par le consortium « Chronic Kidney Disease Epidemiology » (CKD-EPI). Nous verrons également en quoi la cystatine $C$ est une alternative crédible à la créatinine sérique, tout en discutant des raisons qui limitent actuellement la diffusion de ce marqueur plasmatique prometteur du DFG. 


\section{Formules d'estimation du débit de filtration glomérulaire basées sur la créatinine sérique}

\subsection{Principales formules d'estimation}

Les principales équations d'estimation du débit de filtration glomérulaire (DFG) basées sur la concentration sérique de créatinine sont présentées dans le Tableau 1 [1-16].

La relation entre concentration de créatinine et DFG est une hyperbole inverse. Le DFG est donc une fonction de l'inverse du taux de créatinine et toutes les formules d'estimation comprennent le module $\frac{1}{\text { créatinine }}([\text { créatinine }])^{-1,154}$ pour la formule MDRD abré gé e. Les formules d'estimation intègrent par ailleurs, à différents degrés, des facteurs influençant directement la production de créatinine ou des facteurs influençant la masse musculaire (âge, sexe, poids, origine ethnique). Une multitude d'équations ont été développées au fil du temps [17], avec un regain d'activité net depuis la publication de l'équation dite "MDRD » [2] : on parle volontiers actuellement d'« épidémie de formules d'estimation du DFG ». Cette épidémie est le témoin indirect du caractère parfois très approximatif d'une estimation du DFG basée sur les valeurs de concentration sérique de créatinine.

Les formules d'estimation du DFG les plus couramment utilisées chez l'adulte sont les formules Cockcroft et Gault, MDRD et CKD-EPI $[1,2,4]$.

Tableau 1

Principales équations d'estimation du débit de filtration glomérulaire (DFG) basées sur la créatinine sérique.

\begin{tabular}{|c|c|}
\hline Références & Formule \\
\hline $\begin{array}{l}\text { MDRD abrégée }[2,3] \\
\text { Initiale } \\
\text { Corrigée pour créatinine standardisée IDMS }\end{array}$ & 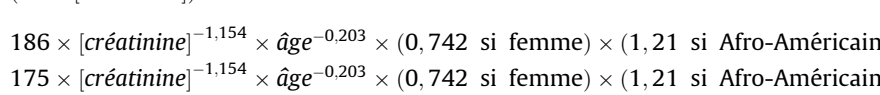 \\
\hline CKD-EPI (créatinine standardisée) [4] & $\begin{array}{l}D F G=A \times\left(\frac{[\text { créatinine }]}{B}\right)^{C} \times 0,993^{\hat{a} g e} \\
\text { Si Noir-Africain, femme et [créatinine] } \leq 62 \mu \mathrm{mol} / 1: \mathrm{A}=166 ; \mathrm{B}=0,7 ; \mathrm{C}=-0,329 \\
\text { Si Noir-Africain, femme et [créatinine] }>62 \mu \mathrm{mol} / \mathrm{l}: \mathrm{A}=166 ; \mathrm{B}=0,7 ; \mathrm{C}=-1,209 \\
\text { Si Noir-Africain, homme et [créatinine] } \leq 80 \mu \mathrm{mol} / 1: \mathrm{A}=163 ; \mathrm{B}=0,9 ; \mathrm{C}=-0,411 \\
\text { Si Noir-Africain, homme et [créatinine] }>80 \mu \mathrm{mol} / \mathrm{l}: \mathrm{A}=163 ; \mathrm{B}=0,9 ; \mathrm{C}=-1,209 \\
\text { Si Caucasien, femme et [créatinine] } \leq 62 \mu \mathrm{mol} / \mathrm{l}: \mathrm{A}=144 ; \mathrm{B}=0,7 ; \mathrm{C}=-0,329 \\
\text { Si Caucasien, femme et [créatinine] }>62 \mu \mathrm{mol} / \mathrm{l}: \mathrm{A}=144 ; \mathrm{B}=0,7 ; \mathrm{C}=-1,209 \\
\text { Si Caucasien, homme et [créatinine] } \leq 80 \mu \mathrm{mol} / \mathrm{l}: \mathrm{A}=141 ; \mathrm{B}=0,9 ; \mathrm{C}=-0,411 \\
\text { Si Caucasien, homme et [créatinine] }>80 \mu \mathrm{mol} / \mathrm{l}: \mathrm{A}=141 ; \mathrm{B}=0,9 ; \mathrm{C}=-1,209\end{array}$ \\
\hline
\end{tabular}

Bjornsson et al. [5]

Hommes : $(27-[0,173 \times \hat{a} g e]) \times$ poids $\times \frac{0,7}{[\text { créatinine }]}$
Femmes : $[(25-[0,175 \times \hat{a} g e])] \times$ poids $\times \frac{0,7}{[\text { créatinine }]}$

Davis et al. [6]

Edwards et White [7]

$\frac{(140-\hat{a} g e)}{\text { [créatinine }]} \times(0,85$ si femme $)$

Hommes : $\frac{94,3}{[\text { créatinine }]}-1,8$
Femmes : $\frac{69,9}{[\text { créatinine }]}-2,2$

Gates [8]

Hommes : $89,4 \times[\text { créatinine }]^{-1,2}+(55-\hat{a g g e}) \times 0,447 \times$ créatinine $^{-1,1}$

Femmes : $60 \times[\text { créatinine }]^{-1,1}+(56-\hat{a g e}) \times 0,3 \times[\text { créatinine }]^{-1,1}$

Hull et al. [9]

$\frac{(145-\hat{a} g e)}{\text { [créatinine }]}-3 \times(0,85$ si femme $)$

Jelliffe [10]

Mawer et al. [11]

$\frac{98-0,8 \times(\hat{a} g e-20)}{\text { [créatinine }]} \times(0,9$ si femme $)$

Hommes : $\frac{\text { poids } \times(29,3-[0,203 \times \text { âge }]) \times(1-0,03 \times[\text { créatinine }])}{14,4 \times[\text { créatinine }] \times \frac{70}{\text { poids }}}$

Femmes : $\frac{\text { poids } \times(25,3-[0,175 \times \hat{a} g e]) \times(1-0,03 \times[\text { créatinine }])}{14,4 \times[\text { créatinine }] \times \frac{70}{\text { poids }}}$

Nankivell et al. [12]

$\frac{6,7}{[\text { créatinine }]}+\frac{\text { poids }}{4}-\frac{[\text { urée }]}{2}-\frac{100}{\text { taille }^{2}}+35$

$\frac{6,7}{[\text { créatinine }]}+\frac{\text { poids }}{4}-\frac{[\text { urée }]}{2}-\frac{100}{\text { taille }^{2}}+25$

Walser et al. [13]

Hommes : 7,57 ([créatinine $] \times 0,0884)^{-1}-0,103 \times$ âge $+0,096 \times$ poids $-6,66$

Femmes : 6, 05 $([\text { créatinine }] \times 0,0884)^{-1}-0,08 \times \hat{a g g e}+0,08 \times$ poids $-4,81$

Mayo Clinic [14]

$e^{\left(1,911+\frac{5,249}{[\text { créatinine }]}-\frac{2,114}{\lfloor\text { créatinine }\rfloor^{2}}-0,00686 \times \hat{a} g e-0,205 \text { si femme }\right)}$

Salazar et Corcoran [15]

Hommes : $\frac{(137-\hat{a} g e) \times\left[(0,285 \times \text { poids })+\left(12,1 \times \text { taille }^{2}\right)\right]}{51 \times[\text { créatinine }]}$

Femmes : $\frac{(146-\hat{a g e}) \times\left[(0,287 \times \text { poids })+\left(9,74 \times \text { taille }^{2}\right)\right]}{60 \times[\text { créatinine }]}$

MDRD7 [2]

$170 \times[\text { créatinine }]^{-0,999} \times \hat{\text { agge }} e^{-0,176} \times[B U N]^{-0,170} \times[\text { albumine }]^{0,318} \times(0,762$ si femme $) \times(1,18$ si Afro-Américain $)$

$3736 \times[\text { créatinine }]^{-0,87} \times \hat{a} g e^{-0,95} \times(0,82$ si femme $)$

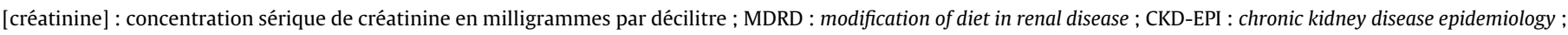
IDMS : isotope dilution mass spectrometry; BIS : Berlin Initiative Study ; BUN : blood urea nitrogen ; [albumine] : concentration sérique d'albumine. 


\subsubsection{Formule de Cockcroft et Gault}

La formule a été développée dans l'esprit d'estimer la clairance de la créatinine en s'affranchissant du recueil urinaire fastidieux et imprécis. Cette formule donne donc une approximation de la clairance de la créatinine et non du DFG tel que mesuré par les méthodes de référence précédemment décrites. Elle tend donc en théorie à surestimer le DFG réel en raison de la prise en compte de la sécrétion tubulaire de créatinine.

La publication initiale date de 1976 et était basée sur une population de 249 patients âgés de 18 à 92 ans ne comprenant que $4 \%$ de femmes. Cette formule comprend plusieurs paramètres à savoir le poids, l'âge, le sexe et bien sûr la créatinine. La méthode de dosage de la créatinine n'est pas connue avec certitude [1].

\subsubsection{Formules MDRD}

La méthode de dérivation des formules MDRD était complètement différente. L'objectif était cette fois-ci de prédire le DFG mesuré par une méthode de référence.

L'échantillon de population utilisé comprenait 1070 patients sur la totalité des 1628 sujets inclus dans l'étude MDRD au cours de laquelle une détermination du DFG par clairance urinaire de l'iothalamate normalisé à la surface corporelle (rapportée à $1,73 \mathrm{~m}^{2}$ ) était réalisée. La population était caractérisée par un âge moyen de 50,6 ans, un indice de masse corporelle de $28 \mathrm{~kg} / \mathrm{m}^{2}$, comprenait $60 \%$ d'hommes et $12 \%$ de Noirs. Le DFG moyen était de $40 \mathrm{ml} / \mathrm{min} / 1,73 \mathrm{~m}^{2}$. La réalisation d'une régression multiple intégrant un grand nombre de variables a permis la dérivation de plusieurs formules de complexité croissante. La formule initialement recommandée prend le nom de MDRD7 [2]. En 2000, l'équipe de Levey publie une nouvelle formule simplifiée dite " abrégée " et comprenant quatre variables : la créatinine sérique, l'âge, le sexe et l'origine ethnique [18]. Plus récemment, une dernière modification a été réalisée permettant d'utiliser cette formule avec une créatininémie standardisée sur la méthode de référence de dosage de créatinine (isotope dilution mass spectrometry [IDMS]) [3]. Cette dernière étape est particulièrement importante dans la mesure où la variabilité analytique liée aux différentes méthodes de dosage de créatinine constitue un facteur d'imprécision à la fois substantiel et maîtrisable dans l'estimation du DFG. La majorité (et idéalement, la totalité) des kits de dosage de créatinine étant raccordée à la méthode IDMS, cette version corrigée de la formule MDRD est actuellement la plus utilisée [19,20]. bas.

Les limitations de cet estimateur du DFG seront détaillées plus

\subsubsection{Formules CKD-EPI}

Très récemment, une nouvelle formule destinée à améliorer les performances prédictives de la formule MDRD au-dessus de $60 \mathrm{ml} /$ $\mathrm{min} / 1,73 \mathrm{~m}^{2}$ a été décrite. Elle a été dérivée d'un échantillon beaucoup plus important (5504 patients) d'âge moyen de 47 ans, d'indice de masse corporelle moyen $28 \mathrm{~kg} / \mathrm{m}^{2}$, avec $32 \%$ de Noirs et ayant un DFG moyen de $68 \mathrm{ml} / \mathrm{min} / 1,73 \mathrm{~m}^{2}$. Sur le plan méthodologique, il faut noter que, là aussi, cette équation a été développée (1) par rapport à un DFG mesuré par clairance urinaire de l'iothalamate indexé à la surface corporelle et (2) en utilisant une créatinine standardisée. Le dosage de créatinine des patients de la cohorte CKD-EPI n'était par contre pas systématiquement, comme cela est parfois rapporté, réalisé selon une technique enzymatique. Cette formule est plus complexe que les précédentes, mais est supérieure à l'équation MDRD dans la population à DFG élevé [4].

\subsection{Méthodologie d'évaluation de la performance des estimateurs du débit de filtration glomérulaire}

Cette évaluation doit comprendre plusieurs conditions permettant la plus grande rigueur d'interprétation. Ces conditions sont en partie précisées par les recommandations Kidney Disease Outcomes Quality Initiative (K/DOQI) [17].

La première condition est l'utilisation d'une méthode de référence de mesure du DFG comme comparateur. La deuxième condition est liée à la population étudiée. Tout d'abord, la taille de l'échantillon détermine la performance statistique et un nombre de mesures minimal de 100 unités est retenu par les K/DOQI. Par ailleurs, la description de la population est un élément fondamental, puisqu'elle détermine l'interprétation des résultats et l'applicabilité des performances des estimateurs dans la pratique clinique. En effet, de nombreux facteurs sont à même de faire varier les performances des estimateurs du DFG basés sur la concentration de la créatinine sérique (âge, poids et indice de masse corporelle, ratio homme/femme, origine ethnique, situation clinique). La troisième condition est la pertinence des critères d'évaluation. Plusieurs aspects de la performance prédictive d'un estimateur doivent en effet être envisagés.

- L'évaluation de la corrélation est réalisée par la détermination du coefficient de corrélation $r$ selon Bravais-Pearson. Elle mesure la force de la relation linéaire existant entre deux variables, ici le DFG estimé et mesuré. Plus $r$ est proche de 1, plus il existe une relation linéaire de type $y=\mathrm{a} x+\mathrm{b}$ entre les deux variables. Cependant, si a et $b$ sont très différents de 1 et 0 respectivement, la justesse et la précision peuvent être faibles avec $r$ proche de 1 . Ce paramètre n'est donc pas suffisant pour évaluer un estimateur et, de plus, n'est pas intuitivement transposable en pratique clinique.

- L'évaluation du biais est le premier paramètre à envisager [21]. Il correspond à l'erreur systématique d'estimation et est déterminé par la moyenne des différences entre le DFG estimé et le DFG mesuré. Il donne donc la justesse d'estimation et permet de conclure à une sur- ou sous-estimation du DFG par la formule étudiée. L'ampleur du biais absolu est très dépendante du niveau de DFG et un autre paramètre, le biais relatif, permet d'exprimer l'erreur systématique en pourcentage du DFG. Ainsi, un biais absolu de $+3 \mathrm{ml} / \mathrm{min} / 1,73 \mathrm{~m}^{2}$ correspond à une surestimation de $10 \%$ du DFG à $30 \mathrm{ml} / \mathrm{min} / 1,73 \mathrm{~m}^{2}$, alors que celle-ci n'est que de $3 \%$ à $100 \mathrm{ml} / \mathrm{min} / 1,73 \mathrm{~m}^{2}$.

- Le deuxième paramètre est la précision, soit la dispersion de l'erreur autour du biais. La mesure la plus simple de ce critère d'évaluation est l'écart-type du biais absolu. Plus celui-ci est faible, plus la dispersion de l'erreur est faible et plus l'estimateur est précis.

- La représentation conjointe du biais et de la précision peut se faire par la méthode de Bland et Altman [21]. Celle-ci prend la forme d'un graphique avec, en abscisse, la moyenne des DFG mesurés et estimés, en ordonnée, la différence entre DFG estimé et DFG mesuré. Chaque mesure est représentée et le nuage de points donne l'impression visuelle de la dispersion des valeurs autour du biais figuré par une ligne horizontale. La précision est représentée par deux lignes comprenant entre elles $95 \%$ des estimations (le biais \pm 2 écarts-types).

- La proportion d'estimations comprises à $\pm x \%$ du DFG mesuré est un paramètre qui intègre, de façon synthétique et aisément transposable pour le clinicien, à la fois le biais et la précision. La proportion pour 30 \% du DFG, appelée justesse 30 \% ou P30, est le paramètre le plus discriminant pour comparer plusieurs estimateurs entre eux.

Enfin, le dernier type de critère d'évaluation correspond aux performances diagnostiques, c'est-à-dire la capacité de l'estimateur à détecter un DFG mesuré inférieur à un seuil (par exemple, $60 \mathrm{ml} /$ $\mathrm{min} / 1,73 \mathrm{~m}^{2}$ ). Il s'agit en fait d'étudier sensibilité, spécificité, valeurs prédictives et aires sous la courbe (ASC ROC). Il est utile de noter que la sensibilité et la spécificité varient en fonction du biais, et une sousestimation du DFG se traduit par une sensibilité élevée. L'étude de l'ASC est plus intéressante, car indépendante du biais. 


\subsection{Validation des estimateurs basés sur la créatinine dans la population générale}

Formules d'estimation du DFG et épidémiologie de la maladie rénale chronique

- Le développement récent des formules basées sur la créatinine pour l'estimation du DFG a largement favorisé les études épidémiologiques sur la prévalence de la maladie rénale chronique. En effet, la mesure du DFG par les méthodes de référence dans une large population est beaucoup plus difficilement envisageable même si elle n'est pas impossible à proprement parler. L'étude épidémiologique américaine National Health and Nutrition Examination Survey (NHANES) rapporte une prévalence de la maladie rénale dans la population générale adulte de $10,82 \%$ si on retient, comme définition de la maladie rénale, un DFG estimé par MDRD inférieur à $60 \mathrm{ml} / \mathrm{min} / 1,73 \mathrm{~m}^{2}$ [22]. Cependant, nous avons vu que la formule MDRD avait une tendance à sous-estimer le DFG chez le sujet sain et cette prévalence de 10,82 \% est donc sans aucun doute surestimée [23]. Dans la même population, la prévalence de la maladie rénale passe à 9,88 \% si la formule CKD-EPI, sensée être plus précise justement chez les patients à DFG normal, est utilisée à la place de la formule MDRD [4]. Cette formule, pour différentes raisons analytiques complexes, ne présente cependant pas toutes les garanties nécessaires à son utilisation en épidémiologie. Il peut aussi apparaître pour le moins étrange que dans ces différentes études épidémiologiques, la maladie rénale de stades 1 et 2 soit largement moins fréquente que celle de stade 3. Cela est expliqué par la classification K/DOQI utilisée dans ces études [17], classification dans laquelle les stades 1 et 2 nécessitent la présence d'un critère d'atteinte rénale en plus de l'estimation du DFG (en pratique pour la plupart des cas, il s'agit de la présence d'une protéinurie) alors que le stade 3 est défini par le seul critère d'un DFG inférieur à $60 \mathrm{ml} / \mathrm{min} / 1,73 \mathrm{~m}^{2}$. Cette limitation est aussi retrouvée dans les dernières recommandations internationales [24].

- Une autre critique fondamentale, avancée à l'égard de ce genre d'étude de prévalence, est l'utilisation, comme critère de maladie rénale, d'un niveau fixe de DFG, en l'occurrence $60 \mathrm{ml} / \mathrm{min} / 1,73 \mathrm{~m}^{2}$. L'utilisation de ce critère figé apparaît quelque peu arbitraire, principalement chez le sujet âgé qui voit, " naturellement ", son DFG diminué avec le temps. Même si les études visant à déterminer l'évolution du DFG avec l'âge sont peu nombreuses, il y a de nombreux arguments indirects pour affirmer qu'une bonne proportion de patients âgés, mais néanmoins sains au niveau néphrologique, ont un DFG inférieur à $60 \mathrm{ml} /$ $\mathrm{min} / 1,73 \mathrm{~m}^{2}$ [25-29]. Cette affirmation est aussi à prendre dans un contexte gériatrique où les formules basées sur la créatinine sont, sans doute, imprécises et biaisées.

- Au total, ces différentes considérations alimentent une polémique qui va bien au-delà de la seule question du dépistage de la maladie rénale chronique par les formules d'estimation du DFG [30,31].
Un grand nombre d'études ont permis l'évaluation des performances des trois principaux estimateurs. Nous avons retenu les études les plus récentes, concernant au moins 100 patients et utilisant une méthode de référence de mesure du DFG. Ces études sont résumées dans les Tableaux 2 et 3.

Les critères de jugement les plus couramment utilisés sont le biais absolu et la P30, et permettent donc la comparaison de ces études entre elles. Les conditions d'interprétation des performances de ces estimateurs doivent intégrer le type de population, le niveau de DFG moyen, la méthode de mesure du DFG, la technique de dosage de créatinine (colorimétrique ou enzymatique).

Parmi les études retenues, deux grands types de population sont à bien différencier : la population de sujets à fonction rénale normale, particulièrement importante dans le cadre, d'une part de l'évaluation des donneurs vivants potentiels et, d'autre part, de la détection de l'insuffisance rénale chronique débutante (études épidémiologiques de prévalence), et la population des patients insuffisants rénaux chroniques (définis, un peu arbitrairement, par un DFG inférieur à $\left.60 \mathrm{ml} / \mathrm{min} / 1,73 \mathrm{~m}^{2}\right)$.

Le premier type de population (fonction rénale normale) est caractérisé par une sous-estimation constante et majeure ( -9 à $-42 \mathrm{ml} / \mathrm{min} / 1,73 \mathrm{~m}^{2}$ ) du DFG par les formules MDRD sur les études retenues. Cela explique les relatives faibles P30 comprises entre $28 \%$ et $86 \%$. L'étude de Rigalleau et al. a trouvé une P30 à $89 \%$, mais par l'intégration dans la formule MDRD originale d'une créatinine obtenue par méthode enzymatique proche du nouveau standard IDMS. Après correction du dosage pour obtenir un référentiel de type Jaffé, la P30 chute à 51 \% [42]. Au total, seule l'étude de Poggio et al. et la sous-population DFG supérieur à $60 \mathrm{ml} / \mathrm{min} / 1,73 \mathrm{~m}^{2}$ de l'étude de Froissart et al. obtiennent une P30 acceptable dans cette population $[37,43]$. Toutes les autres publications ayant étudié MDRD dans une population avec un DFG supérieur à $60 \mathrm{ml} / \mathrm{min} /$ $1,73 \mathrm{~m}^{2}$ ont insisté sur sa faible performance et sur sa tendance systématique à la sous-estimation du DFG (Tableau 2). Ces résultats sont expliqués, en partie, par la population de dérivation de la formule MDRD, ne comportant que des sujets présentant un DFG inférieur à $60 \mathrm{ml} / \mathrm{min} / 1,73 \mathrm{~m}^{2}$.

La formule de Cockcroft et Gault est évaluée dans cette population par six études et globalement, le biais est moins clairement négatif $(-26,5$ à $+16,8)$; la P30 est comprise entre $58 \%$ et $88 \%$, avec une supériorité sur la formule MDRD dans quatre de ces études, une équivalence ou une infériorité dans deux études. Le développement de la formule de la Mayo Clinic était destiné à améliorer les performances prédictives dans cette population, intégrant une forte proportion de donneurs vivants potentiels (580 sur un total de 900 patients) [14]. Cependant, deux études tendent à montrer une surestimation importante du DFG dans cette population par cette formule [64,65].

La formule CKD-EPI a été développée pour améliorer les performances au-dessus de $60 \mathrm{ml} / \mathrm{min} / 1,73 \mathrm{~m}^{2}$. La publication initiale comprend un groupe de validation externe avec 1984 patients présentant un DFG supérieur à $60 \mathrm{ml} / \mathrm{min} / 1,73 \mathrm{~m}^{2}$, chez qui cette nouvelle équation présente une P30 à 88,3\% contre $84,7 \%$ avec MDRD. L'amélioration sur le biais était encore plus marquée (biais médian $-3,5 \mathrm{ml} / \mathrm{min} / 1,73 \mathrm{~m}^{2}$ contre $-10,6 \mathrm{ml} / \mathrm{min} /$ $1,73 \mathrm{~m}^{2}$ ) avec la formule CKD-EPI au-delà de $60 \mathrm{ml} / \mathrm{min} / 1,73 \mathrm{~m}^{2}$ [4]. Malgré ces améliorations, le gain en termes de précision reste très limité avec cette nouvelle formule, y compris chez le patient à fonction rénale normale ou peu altérée. Globalement, l'équation CKD-EPI a une valeur ajoutée peu contestable sur le plan épidémiologique. La supériorité de l'équation CKD-EPI par rapport à l'équation MDRD pour évaluer le DFG à l'échelon individuel est par contre discutable. En la matière, l'intérêt du clinicien (évaluation du degré d'insuffisance rénale pour un individu donné) peut différer de celui de l'épidémiologiste (dépistage de la maladie rénale chronique dans une population donnée) [66]. 
Tableau 2

Principales études comparant la performance des équations modification of diet in renal disease (MDRD) et Cockcroft-Gault.

\begin{tabular}{|c|c|c|c|c|c|c|c|c|}
\hline \multirow[t]{2}{*}{ Références } & \multirow[t]{2}{*}{ Population } & \multirow[t]{2}{*}{$\begin{array}{l}\text { DFG moyen } \\
\left(\mathrm{ml} / \mathrm{min} / 1,73 \mathrm{~m}^{2}\right)\end{array}$} & \multirow[t]{2}{*}{$\begin{array}{l}\text { Dosage de la } \\
\text { créatinine }\end{array}$} & \multirow[t]{2}{*}{$\begin{array}{l}\text { Méthode de } \\
\text { référence }\end{array}$} & \multicolumn{2}{|c|}{$\begin{array}{l}\text { Biais } \\
\left(\mathrm{ml} / \mathrm{min} / 1,73 \mathrm{~m}^{2}\right)\end{array}$} & \multicolumn{2}{|c|}{ P30 \% } \\
\hline & & & & & $C-G$ & $M D R D a$ & $C-G$ & $M D R D a$ \\
\hline Lewis et al. [32] & 1703 Afro-Américains & 56,9 & Jaffé & Iothalamate & $+4,8$ & $-6,1$ & - & $88 \%$ \\
\hline Bostom et al. [33] & $\begin{array}{l}109 \text { patients atteints de maladie rénale } \\
\text { chronique, [créatinine] }<1,5 \mathrm{mg} / \mathrm{dl}\end{array}$ & 109 & Jaffé & Iohexol & $-26,5$ & $-41,7$ & $59 \%$ & $28 \%$ \\
\hline Lin et al. [34] & 100 donneurs vivants & 113 & Jaffé & $\begin{array}{l}\text { Iothalamate } \\
(n=55) \\
\left({ }^{99 \mathrm{~m}} \mathrm{Tc}\right)-\mathrm{DTPA} \\
(n=45)\end{array}$ & $+16,8$ & $-18,3$ & $58 \%$ & $65 \%$ \\
\hline Hallan et al. [35] & $\begin{array}{l}215 \text { atteints d'insuffisance rénale } \\
\text { chronique et donneurs vivants }\end{array}$ & 49,8 & Jaffé & $\left({ }^{51} \mathrm{Cr}\right)-\mathrm{EDTA}$ & - & - & $49 \%$ & $62 \%$ \\
\hline \multirow[t]{2}{*}{ Rule et al. [14] } & 580 pas d'insuffisance rénale chronique & $101[63-177]$ & Jaffé & Iothalamate & - & -29 & - & $54 \%$ \\
\hline & $\begin{array}{l}320 \text { patients avec insuffisance rénale } \\
\text { chronique }\end{array}$ & $48[5-133]$ & Jaffé & Iothalamate & - & $-5,5$ & - & $75 \%$ \\
\hline Rule et al. [36] & 365 donneurs vivants & 101 & Jaffé & Iothalamate & -14 & -29 & $82 \%$ & $55 \%$ \\
\hline \multirow[t]{2}{*}{ Poggio et al. [37] } & 828 atteints d'insuffisance rénale chronique & $32[10-74]$ & Jaffé & Iothalamate & $+3,5$ & $-0,5$ & $60 \%$ & $71 \%$ \\
\hline & 457 donneurs vivants & $106[85-130]$ & Jaffé & Iothalamate & $+1,9$ & -9 & $85 \%$ & $86 \%$ \\
\hline Poggio et al. [38] & 107 patients hospitalisés & 17,1 & Jaffé & Iothalamate & $+8,9$ & $+6,8$ & $26 \%$ & $31 \%$ \\
\hline Ibrahim et al. [39] & 1286, diabète $\mathrm{I}$, [créatinine] < 1,2 mg/dl & 122 & Jaffé & Iothalamate & -6 & -22 & $88 \%$ & $78 \%$ \\
\hline Cirillo et al. [40] & $\begin{array}{l}380 \text { atteints d'insuffisance rénale } \\
\text { chronique ou non }\end{array}$ & 76 [8-159] & Jaffé & Inuline & $-5,2$ & $-6,1$ & $68 \%$ & $72 \%$ \\
\hline Grubb et al. [41] & 451 tout-venant & $63[11-124]$ & Enzymatique & Iohexol & - & $+11,8$ & - & $71 \%$ \\
\hline Rigalleau et al. [42] & 160 diabétiques & 60,9 & Jaffé & $\left({ }^{51} \mathrm{Cr}\right)-\mathrm{EDTA}$ & $+4,8$ & $-6,1$ & - & - \\
\hline Froissart et al. [43] & $\begin{array}{l}2095 \text { dont } 1933 \text { atteints d'insuffisance } \\
\text { rénale chronique }\end{array}$ & 61,1 & Jaffé & $\left({ }^{51} \mathrm{Cr}\right)-\mathrm{EDTA}$ & $+1,9$ & -1 & $79 \%$ & $87 \%$ \\
\hline Verhave et al. [44] & 850, [créatinine] $<1,5 \mathrm{mg} / \mathrm{dl}$ & 99,3 & Enzymatique & $\left({ }^{99 \mathrm{~m}} \mathrm{Tc}\right)-\mathrm{DTPA}$ & $-4,9$ & $-12,4$ & $87 \%$ & $89 \%$ \\
\hline
\end{tabular}

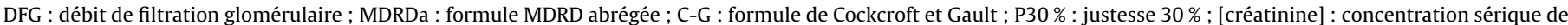
créatinine ; DTPA : acide diéthylène triamine penta-acétique ; EDTA : acide éthylène diamine tétra-acétique.

En conclusion, dans une population sans insuffisance rénale, la formule de Cockcroft et Gault ne semble pas moins performante que la formule MDRD. Toutefois, la formule de Cockcroft et Gault n'a pas été spécifiquement adaptée pour pouvoir être utilisée avec des valeurs de créatininémie standardisées par IDMS. Dans cette population, la formule CKD-EPI offre une performance supérieure aux formules de Cockcroft et Gault et MDRD.

Dans la population des patients insuffisants rénaux chroniques (DFG $<60 \mathrm{ml} / \mathrm{min} / 1,73 \mathrm{~m}^{2}$ ), la formule MDRD semble globalement plus performante que la formule de Cockcroft et Gault puisque les études évaluant les deux formules retrouvent une P30 supérieure $[35,37,40,43]$. Cette P30 s'étend de $62 \%$ à $88 \%$ pour MDRD contre $49 \%$ à $79 \%$ pour Cockcroft et Gault. La formule MDRD tend à une discrète sous-estimation dans cette population $(-0,5$ à $-6,1)$. La formule CKD-EPI offre une performance similaire, voire légèrement inférieure, à la formule MDRD dans cette population (P30 $79,9 \%$ contre $77,2 \%$; biais médian $2,1 \mathrm{ml} / \mathrm{min} / 1,73 \mathrm{~m}^{2}$ contre 3,4 ) $[4,45,67]$.

Une évaluation supplémentaire de la formule CKD-EPI par des équipes indépendantes du groupe de travail CKD-EPI a permis de valider cette formule dans la population de patients à fonction rénale normale ou proche de la normale (Tableau 3) [68].

\subsection{Performances des estimateurs dans différentes populations}

\subsubsection{Effet de l'âge}

L'âge avancé est caractérisé par une diminution de la masse musculaire et donc de la production de créatinine. Ainsi, à concentration de créatinine égale, le patient le plus âgé a le DFG le plus faible. Le paramètre de l'âge est intégré à tous les estimateurs du DFG basés sur la créatinine mais avec un " poids " statistique différent. Le poids de l'âge sur l'estimation du DFG par la formule de Cockcroft et Gault est excessif après 70 ans et rend la formule inutilisable après 80 ans, comme l'ont montré Froissart et Rossert [69]. Ces auteurs ont montré une sous-estimation très importante du DFG par la formule de Cockcroft et Gault après 65 ans chez les hommes $\left(-14,5 \mathrm{ml} / \mathrm{min} / 1,73 \mathrm{~m}^{2}\right.$ contre $+3,2$ avant 65 ans) avec un effet similaire chez les femmes à DFG élevé.
L'amplitude était moins marquée à bas DFG ( $\left.<60 \mathrm{ml} / \mathrm{min} / 1,73 \mathrm{~m}^{2}\right)$ [22]. Dans une étude concernant 46 patients âgés de 69 à 92 ans, Lamb et al. retrouvent un biais à $-11,1 \mathrm{ml} / \mathrm{min} / 1,73 \mathrm{~m}^{2}$ avec la formule de Cockcroft et Gault alors qu'il n'était que de $-2,0 \mathrm{ml} /$ $\mathrm{min} / 1,73 \mathrm{~m}^{2}$ avec MDRD [70]. Poggio et al. ont décrit également le même effet par une étude multifactorielle qui retrouve pour chaque augmentation de $10 \%$ de l'âge, une diminution en moyenne de $1,8 \mathrm{ml} / \mathrm{min} / 1,73 \mathrm{~m}^{2}$ de DFG mesuré (iothalamate), de $1,9 \mathrm{ml} /$ $\mathrm{min} / 1,73 \mathrm{~m}^{2}$ de DFG estimé par MDRD et 3,6 ml/min $/ 1,73 \mathrm{~m}^{2}$ de DFG estimé par Cockcroft et Gault [37]. De la même manière, dans une étude portant sur 48 patients issus d'un milieu gériatrique (moyenne d'âge 86 ans), la formule de Cockcroft et Gault sousestimait de façon majeure le DFG (biais moyen $-6,7 \mathrm{ml} / \mathrm{min} /$ $1,73 \mathrm{~m}^{2}$ ) [71].

En conclusion, la formule de Cockcroft et Gault ne doit pas être utilisée après 70 ans. Pour autant, l'utilisation exclusive de l'équation CKD-EPI dans cette population ne va pas sans poser des problèmes. Ses performances sont également nettement altérées pour l'évaluation du DFG de la personne âgée $[16,72,73]$. L'utilisation d'un estimateur spécifique au sujet âgé, à l'instar de ce qui est proposé en pédiatrie, pourrait être la solution [16]. A cet égard, l'équation de la Berlin Initiative Study (BIS) récemment développée et validée semble être un estimateur très performant dont la place en pratique clinique devra être précisée dans le futur.

\subsubsection{Effet du poids}

Le rôle du poids dans les performances des estimateurs est complexe. La question la plus importante dans ce cadre est le comportement des estimateurs chez les patients obèses. En effet, l'obésité est bien sûr liée à une accumulation de masse grasse, n'entraînant en elle-même aucune surproduction de créatinine, mais également une augmentation modérée de masse musculaire qui, elle, peut rendre compte d'un surcroît de concentration sans différence de DFG. Cependant, il existe une grande hétérogénéité entre les patients concernant le rapport entre la masse musculaire du patient et son poids. C'est pourquoi la formule de Cockcroft et Gault qui intègre le poids comme facteur de variation peut en 
Tableau 3

Principales études comparant la performance des équations MDRD et CKD-EPI.

\begin{tabular}{|c|c|c|c|c|c|c|c|c|}
\hline \multirow[t]{2}{*}{ Références } & \multirow[t]{2}{*}{ Population } & \multirow{2}{*}{$\begin{array}{l}\text { DFG moyen } \\
\left(\mathrm{ml} / \mathrm{min} / 1,73 \mathrm{~m}^{2}\right)\end{array}$} & \multirow{2}{*}{$\begin{array}{l}\text { Dosage de } \\
\text { la créatinine }{ }^{a}\end{array}$} & \multirow{2}{*}{$\begin{array}{l}\text { Méthode } \\
\text { de référence }\end{array}$} & \multicolumn{2}{|c|}{ Biais $^{\mathrm{b}}\left(\mathrm{ml} / \mathrm{min} / 1,73 \mathrm{~m}^{2}\right)$} & \multicolumn{2}{|l|}{ P30 \% } \\
\hline & & & & & $M D R D$ & $C K D-E P I$ & MDRD & $C K D-E P I$ \\
\hline Murata et al. [45] & $\begin{array}{l}5238 \\
\text { Diverses populations }\end{array}$ & 56 & Jaffé & Iothalamate & $-4,1$ & $-0,7$ & $78 \%$ & $78 \%$ \\
\hline Levey et al. [4] & $\begin{array}{l}3896 \\
\text { Diverses populations }\end{array}$ & 68 & Jaffé & Iothalamate & 5,5 (médiane) & 2,5 (médiane) & $81 \%$ & $84 \%$ \\
\hline Eriksen et al. [46] & $\begin{array}{l}1621 \\
\text { Population générale }\end{array}$ & 92 & Enzymatique & Iohexol & 1,3 (médiane) & 2,9 (médiane) & $93 \%$ & $95 \%$ \\
\hline Bjork et al. [47] & $\begin{array}{l}1397 \\
\text { Diverses populations }\end{array}$ & 44 & Enzymatique & Iohexol & -2 & 2 & $80 \%$ & $79 \%$ \\
\hline Buron et al. [48] & $\begin{array}{l}1249 \\
\text { Greffés rénaux }\end{array}$ & 54 & Jaffé & Inuline & -1 & 4 & $85 \%$ & $81 \%$ \\
\hline Nyman et al. [49] & $\begin{array}{l}850 \\
\text { Diverses populations }\end{array}$ & 55 & Enzymatique & Iohexol & 1 & 4 & $80 \%$ & $80 \%$ \\
\hline Iliadis et al. [50] & $\begin{array}{l}448 \\
\text { Diabétiques de type } 2\end{array}$ & 73 & Jaffé & $\left({ }^{51} \mathrm{Cr}\right)-\mathrm{EDTA}$ & 8 & 7 & $79 \%$ & $81 \%$ \\
\hline Lane et al. [51] & $\begin{array}{l}425 \\
\text { Pré- et postnéphrectomie }\end{array}$ & 50 (médiane) & Jaffé & Iothalamate & $\begin{array}{l}-1 \\
\text { (médiane) }\end{array}$ & $\begin{array}{l}-2 \\
\text { (médiane) }\end{array}$ & $75 \%$ & $80 \%$ \\
\hline Cirillo et al. [52] & $\begin{array}{l}356 \\
\text { Diverses populations }\end{array}$ & 72 & Jaffé & Inuline & -5 & -1 & $87 \%$ & $88 \%$ \\
\hline Michels et al. [53] & $\begin{array}{l}271 \\
\text { Diverses populations }\end{array}$ & 73 & Enzymatique & Iothalamate & 1 & 5 & $81 \%$ & $85 \%$ \\
\hline Tent et al. [54] & $\begin{array}{l}253 \\
\text { Prénéphrectomie } \\
253 \\
\text { Postnéphrectomie }\end{array}$ & $\begin{array}{l}103 \\
66\end{array}$ & Jaffé & Iothalamate & $\begin{array}{l}-22 \\
-15\end{array}$ & $\begin{array}{l}-14 \\
-10\end{array}$ & $\begin{array}{l}73 \% \\
71 \%\end{array}$ & $\begin{array}{l}89 \% \\
89 \%\end{array}$ \\
\hline Teo et al. [55] & $\begin{array}{l}232 \\
\text { Insuffisants rénaux }\end{array}$ & 52 & Enzymatique & $\left({ }^{99 \mathrm{~m}} \mathrm{Tc}\right)-\mathrm{DTPA}$ & -1 & 1 & $80 \%$ & $83 \%$ \\
\hline White et al. [56] & $\begin{array}{l}207 \\
\text { Greffés rénaux }\end{array}$ & 58 & Jaffé & $\left({ }^{99 \mathrm{~m}} \mathrm{Tc}\right)-\mathrm{DTPA}$ & -8 & -5 & $79 \%$ & $84 \%$ \\
\hline $\begin{array}{l}\text { Redal-Baigorri } \\
\text { et al. [57] }\end{array}$ & $\begin{array}{l}185 \\
\text { Patients oncologiques }\end{array}$ & 85 & Jaffé & $\left({ }^{51} \mathrm{Cr}\right)-\mathrm{EDTA}$ & 1 & 1 & $89 \%$ & $90 \%$ \\
\hline Poge et al. [58] & $\begin{array}{l}170 \\
\text { Greffés rénaux }\end{array}$ & 40 & Jaffé & $\left({ }^{99 \mathrm{~m}} \mathrm{Tc}\right)-\mathrm{DTPA}$ & 5 & 8 & $72 \%$ & $64 \%$ \\
\hline Jones [59] & $\begin{array}{l}169 \\
\text { Diverses populations }\end{array}$ & 71 & Jaffé & $\left({ }^{99 \mathrm{~m}} \mathrm{Tc}\right)-\mathrm{DTPA}$ & & & $81 \%$ & $86 \%$ \\
\hline Kukla et al. [60] & $\begin{array}{l}107 \\
\text { Greffés rénaux }\end{array}$ & 56 & Jaffé & Iothalamate & 8 & 13 & $72 \%$ & $59 \%$ \\
\hline Silveiro et al. [61] & $\begin{array}{l}105 \\
\text { Diabétiques de type } 2\end{array}$ & 103 & Jaffé & $\left({ }^{51} \mathrm{Cr}\right)-\mathrm{EDTA}$ & -25 & -20 & $64 \%$ & $67 \%$ \\
\hline Orskov et al. [62] & $\begin{array}{l}101 \\
\text { Patients atteints de } \\
\text { polykystose }\end{array}$ & 64 & Enzymatique & $\left({ }^{51} \mathrm{Cr}\right)-\mathrm{EDTA}$ & -11 & -5 & $83 \%$ & $90 \%$ \\
\hline $\begin{array}{l}\text { Praditprnsilpa } \\
\text { et al. [63] }\end{array}$ & $\begin{array}{l}100 \\
\text { Insuffisants rénaux }\end{array}$ & 51 & Enzymatique & $\left({ }^{99 m} \mathrm{Tc}\right)-\mathrm{DTPA}$ & -9 & -8 & $63 \%$ & $68 \%$ \\
\hline
\end{tabular}

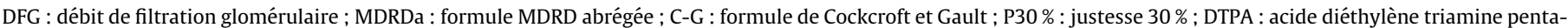
acétique ; EDTA : acide éthylène diamine tétra-acétique.

a Toutes les mesures de la concentration de créatinine sont standardisées sur la méthode de référence par isotope dilution mass spectrometry (IDMS).

b Le biais est défini comme la différence moyenne entre DFG estimé et mesuré, sauf note contraire.

théorie surestimer le DFG chez les patients obèses [43]. De plus, la normalisation à la surface corporelle de la formule de Cockcroft et Gault, actuellement recommandée, est critiquable du fait de la non-linéarité de la relation entre le DFG et la surface corporelle et donc de l'absence de base physiologique à cette recommandation. Cette normalisation a peu d'effet à surface corporelle proche de $1,73 \mathrm{~m}^{2}$, mais peut entraîner un biais non négligeable à surface corporelle importante, ce qui est le cas des patients obèses $[74,75]$.

Froissart et al. ont étudié l'effet de l'indice de masse corporelle sur les formules de Cockcroft et Gault et MDRD avec les constatations suivantes : pour un indice de masse corporelle supérieur à $30 \mathrm{~kg} / \mathrm{m}^{2}$, il existait une discrète sous-estimation $\left(-2,6 \mathrm{ml} / \mathrm{min} / 1,73 \mathrm{~m}^{2}\right)$ avec la formule MDRD, alors que l'équation de Cockcroft et Gault surestimait le DFG de façon majeure $(+8,5 \mathrm{ml} /$ $\min / 1,73 \mathrm{~m}^{2}$ ). Les deux formules présentaient des performances médiocres chez les patients dénutris (indice de masse corporelle inférieure à $18,5 \mathrm{~kg} / \mathrm{m}^{2}$ ) avec une surestimation importante du DFG $\left(+12,2\right.$ pour MDRD et $+6,2 \mathrm{ml} / \mathrm{min} / 1,73 \mathrm{~m}^{2}$ pour le calcul selon Cockcroft et Gault) [43]. Poggio et al. ont montré qu'une augmentation moyenne de 10 \% du poids n'entraînait pas de variation du DFG mesuré par clairance de l'iothalamate $(-0,1 \mathrm{ml} /$ $\mathrm{min} / 1,73 \mathrm{~m}^{2}$ ), pas de variation du DFG estimé par MDRD (pas d'intégration du poids comme paramètre), mais, en revanche, une variation en moyenne de $+5 \%$ du DFG estimé par Cockcroft et Gault [37]. Il apparaît donc que la prise en compte du poids par la formule Cockcroft et Gault est excessive et ce de façon substantielle chez les patients obèses (surestimation du DFG) et que la créatinine n'est pas un bon marqueur du DFG en cas de dénutrition majeure, quelle que soit la formule utilisée. Enfin, chez le patient obèse, la performance globale de l'équation CKD-EPI est sensiblement la même que celle de MDRD [76].

De la même manière, les formules d'estimation du DFG basées sur la créatinine surestiment de façon majeure la fonction rénale des patients cirrhotiques en raison de leur dénutrition mais aussi du fait de l'augmentation du volume extracellulaire.

\subsubsection{Effet du sexe}

Le genre des sujets influe sur le taux de créatinine par les différences de masse musculaire entre hommes et femmes. À DFG égal, un homme présente un taux de créatinine supérieur à celui 
d'une femme. Toutes les formules d'estimation intègrent ce paramètre. Froissart et al. ont évalué les performances d'estimation en fonction du sexe et ne retrouvent pas de différence avec la formule de Cockcroft et Gault et une discrète sous-estimation du DFG par la formule MDRD chez les femmes de moins de 65 ans $\left(-3 \mathrm{ml} / \mathrm{min} / 1,73 \mathrm{~m}^{2}\right)[43]$.

\subsubsection{Effet de l'ethnie}

Le facteur ethnique de variation du taux de créatinine à DFG constant est lui aussi directement lié à la masse musculaire. La formule MDRD intègre un facteur correctif pour les patients noirs dits " afro-américains ». Ce facteur multiplicatif est de 1,18 pour la formule MDRD7 et 1,21 pour la formule MDRD abrégée et correspond à la masse musculaire plus importante de ces patients par rapport à la population dite " caucasienne ". Ce facteur a été ultérieurement validé par les données de l'étude African American Study of Kidney Disease and Hypertension (AASK) (1703 patients afro-américains insuffisants rénaux chroniques) [32]. Ces considérations ethniques sont également intégrées à l'équation CKD-EPI [77].

Plusieurs études sur différentes populations asiatiques ont tenté de définir un facteur correctif. Cependant, ce type de correction n'est pas encore complètement validé [78-80].

\subsubsection{Population des patients transplantés}

En transplantation rénale, l'estimation du DFG permet le suivi de la fonction du greffon. Il existe des facteurs propres à cette situation clinique, à même de faire varier les performances des estimateurs basés sur la créatinine (rein unique, état nutritionnel, sécrétion tubulaire de créatinine, rôle des traitements immunosuppresseurs). La formule de Nankivell a été dérivée à partir d'une population de patients transplantés rénaux avec pour objectif une amélioration de la prédiction [12]. Cependant, elle intègre la concentration d'urée comme marqueur, alors que de nombreux facteurs indépendants du DFG sont susceptibles de la faire varier (perfusion rénale, état nutritionnel, apport protidique).

De multiples études ont évalué les performances des estimateurs du DFG en transplantation rénale avec des effectifs compris entre 81 et 1297 (Tableau 4). Elles montrent :

- des performances médiocres de la formule de Nankivell, avec une surestimation importante et des P30 plus faibles que celles des formules MDRD et de Cockcroft et Gault ;

- une surestimation modérée du DFG par la formule MDRD, ce qui contraste avec le biais plutôt négatif dans la population générale à DFG moyen comparable, suggérant un facteur propre à la transplantation diminuant le taux de créatinine à fonction rénale égale (sécrétion tubulaire, dénutrition) ;

- des performances (P30) des formules MDRD et de Cockcroft et Gault inférieures à celles de la population générale à DFG équivalent (avec toutefois une supériorité de la formule MDRD retrouvée par la plupart des études).

Ces résultats incitent donc à la prudence lors de l'utilisation des estimateurs en transplantation rénale et tout particulièrement au cours des essais cliniques où le DFG est le critère de jugement principal [90,93]. L'utilisation des méthodes de référence de mesure du DFG est donc préférable pour le suivi de la fonction du greffon, que ce soit en clinique ou dans les études.

Concernant la formule CKD-EPI, plusieurs études ont souligné qu'elle ne permettait pas d'améliorer la performance d'estimation par rapport à la formule MDRD [48,91].

En transplantation cardiaque, on retrouve une surestimation majeure par toutes les formules d'estimation basées sur la créatinine [94]. En transplantation hépatique, la réduction de la masse musculaire explique en grande partie les performances médiocres des estimateurs basés sur la créatinine. Gerhardt et al. ont retrouvé une surestimation massive du DFG par la formule MDRD (+10 $\left.\mathrm{ml} / \mathrm{min} / 1,73 \mathrm{~m}^{2}\right)$ alors que le DFG moyen était inférieur à $60 \mathrm{ml} / \mathrm{min} / 1,73 \mathrm{~m}^{2}$. La P30 était également médiocre (64\%) [95]. Gonwa et al. ont retrouvé en revanche une sousestimation globale du DFG par MDRD avant et après transplantation hépatique, mais lorsque celui-ci était inférieur à $40 \mathrm{ml} / \mathrm{min} /$ $1,73 \mathrm{~m}^{2}$, MDRD le surestimait de façon majeure $(+22 \mathrm{ml} / \mathrm{min} /$ $1,73 \mathrm{~m}^{2}$ ) [96]. Cela illustre, une fois de plus, les mauvaises performances des estimateurs chez des patients à état général très altéré [38,97].

\section{Cystatine C comme marqueur alternatif du débit de filtration glomérulaire}

\subsection{Bases physiologiques}

La cystatine $\mathrm{C}$ fait partie de la famille des cystatines qui sont des inhibiteurs naturels des cystéines protéinases (telles que les cathepsines $\mathrm{B}, \mathrm{H}$ et $\mathrm{L}$ et les calpaïnes). Ces cystéines protéinases exercent un rôle important dans le catabolisme intracellulaire des peptides et protéines, au niveau du processus de protéolyse de

Tableau 4

Principales études évaluant les estimateurs du débit de filtration glomérulaire (DFG) en transplantation rénale.

\begin{tabular}{|c|c|c|c|c|c|}
\hline Références & $n$ & Dosage de la créatinine & $\begin{array}{l}\text { Calibration de } \\
\text { la créatinine }\end{array}$ & Mesure du DFG & $\begin{array}{l}\text { DFG moyen } \pm \text { DS } \\
\left(\mathrm{ml} / \mathrm{min} / 1,73 \mathrm{~m}^{2}\right)\end{array}$ \\
\hline Mariat et al. [81] & 476 & Enzymatique & Non & Inuline & $47 \pm 16$ \\
\hline Bosma et al. [82] & 798 & Jaffé & Non & Iothalamate & $55 \pm 18(\mathrm{ml} / \mathrm{min})$ \\
\hline Gaspari et al. [83] & 196 & Jaffé & Non & Iohexol & $56,1 \pm 15$ \\
\hline Rule et al. [84] & 103 & Jaffé & Non & Iothalamate & $52 \pm 18$ \\
\hline Raju et al. [85] & 81 & Enzymatique & Non & $\left({ }^{99 \mathrm{~m}} \mathrm{Tc}\right)-\mathrm{DTPA}$ & $59 \pm 24(\mathrm{ml} / \mathrm{min})$ \\
\hline Poge et al. [86] & 95 & Jaffé & Non & $\left({ }^{99 \mathrm{~m}} \mathrm{Tc}\right)-\mathrm{DTPA}$ & 37,4 \\
\hline Poge et al. [87] & 108 & Jaffé & Non & $\left({ }^{99 \mathrm{~m}} \mathrm{Tc}\right)-\mathrm{DTPA}$ & 39,5 \\
\hline Poggioet al. [88] & 209 & Jaffé & Oui & Iothalamate & $44 \pm 26$ \\
\hline White et al. [89] & 117 & Jaffé & Oui & $\left({ }^{99 \mathrm{~m}} \mathrm{Tc}\right)-\mathrm{DTPA}$ & $58 \pm 23$ \\
\hline Maillard et al. [90] & 120 & Enzymatique & Oui & Inuline & $52,6 \pm 19$ \\
\hline Masson et al. [91] & 825 & Enzymatique & Oui & $\begin{array}{l}\text { Inuline } \\
\left({ }^{51} \mathrm{Cr}\right)-\mathrm{EDTA}\end{array}$ & $50 \pm 17$ \\
\hline Bargnoux et al. [92] & 85 & Enzymatique & Oui & $\left({ }^{99 \mathrm{~m}} \mathrm{Tc}\right)-\mathrm{DTPA}$ & $82,7 \pm 21$ \\
\hline White et al. [56] & 207 & Jaffé & Oui & $\left({ }^{99 \mathrm{~m}} \mathrm{Tc}\right)-\mathrm{DTPA}$ & $58 \pm 22$ \\
\hline Poge et al. [58] & 170 & Jaffé & Oui & $\left({ }^{99 \mathrm{~m}} \mathrm{Tc}\right)-\mathrm{DTPA}$ & 39,6 \\
\hline Buron et al. [48] & 1297 & Jaffé & Oui & Inuline & $54 \pm 18$ \\
\hline Kukla et al. [60] & 107 & Jaffé & Oui & Iothalamate & $55,5 \pm 17$ \\
\hline
\end{tabular}

DS : déviation standard ; DTPA : acide diéthylène triamine penta-acétique ; EDTA : acide éthylène diamine tétra-acétique. 
pro-hormones et pro-enzymes, au niveau de la destruction du collagène, dans l'effraction des membranes basales par les cellules cancéreuses. L'intérêt potentiel de la cystatine C comme marqueur biologique du DFG remonte aux années 1980 [98].

Les études physiologiques spécifiques au comportement rénal de la cystatine $C$ sont relativement peu nombreuses et la principale a été réalisée chez le rat [99]. Après avoir été filtrée sans limitation par les glomérules du fait de sa faible masse moléculaire (13 $260 \mathrm{Da}$ ) et l'absence de liaison aux protéines plasmatiques, la cystatine $C$ est entièrement réabsorbée par les tubules proximaux, où elle est presque totalement catabolisée $[99,100]$. La réabsorption tubulaire se ferait par un récepteur, la mégaline, commun à de nombreuses protéines, grâce à un mécanisme d'endocytose [101]. Il est couramment admis qu'il n'existe pas de sécrétion tubulaire de la cystatine $C$, même si une étude chez l'homme a publié des données pouvant indiquer le contraire [102]. Cependant, la méthodologie de cette étude a été largement critiquée et ses conclusions doivent être interprétées avec réserve [103].

La cystatine $C$ est produite par toutes les cellules nucléées de l'organisme chez l'homme. La cystatine $C$ est codée par un gène de ménage, c'est-à-dire un gène exprimé de façon constitutive et non régulée, ce qui est l'argument classique étayant la constance de sa production [100,104].

Cette production constante de cystatine C a longtemps été considérée comme absolue, notamment au vu d'études de cohorte qui n'avaient pu relier la production de la protéine à une situation physiopathologique autre que l'atteinte de la filtration glomérulaire [104]. De nombreuses observations, in vitro et cliniques, relativisent aujourd'hui cette notion.

\subsubsection{Déterminants physiologiques de la production de cystatine $C$}

Parmi les facteurs extrarénaux pouvant influencer les valeurs de cystatine $C$ chez des sujets sains, les travaux les plus récents ont montré que chez les adultes de moins de 60 ans, les concentrations de cystatine $C$ sont plus faibles chez les femmes que chez les hommes, cette différence disparaissant au-delà de 60 ans [105,106].

L'âge est également un facteur de variabilité de la cystatine $C$. Ainsi, des valeurs plus élevées sont retrouvées chez les nouveaunés quels que soient le sexe, le poids ou la taille des enfants, y compris les prématurés [107] ; elles déclinent après la naissance pour rejoindre des valeurs identiques à celles de l'adulte à l'âge de 4 ans. Il convient cependant d'être prudent, en particulier pour les très jeunes enfants et les prématurés, chez qui les valeurs élevées de cystatine $C$ pourraient refléter un DFG bas dans le cadre d'un processus de maturation rénale [107]. Chez l'adulte, la plupart des études montrent une influence significative de l'âge sur les concentrations de cystatine $C$, impliquant des valeurs de référence différentes pour les sujets de plus de 50-60 ans [105,108].

\subsubsection{Influence de la masse musculaire}

Le défaut principal de la créatinine est bien la dépendance de sa production à la masse musculaire [109]. Dans un premier temps, Vinge et al. ont décrit la cystatinémie comme indépendante de la masse musculaire [110]. Néanmoins, cette étude a été récemment critiquée, tant pour la méthodologie clinique que statistique. MacDonald et al. ont, récemment, et de façon plus convaincante, démontré que la cystatinémie était bien, en partie, dépendante de la masse musculaire (DFG déterminé par mesure de la clairance de l'inuline et masse maigre mesurée par densitométrie). L'influence de la masse musculaire sur la production de cystatine $C$ s'explique par le fait que les cellules musculaires sont les plus nombreuses des cellules nucléées de l'organisme [111]. Cependant, il n'en reste pas moins que la variabilité de la cystatine $C$ expliquée par la masse musculaire est bien moindre que pour la créatinine. L'avantage de la cystatine $C$ sur la créatinine chez le patient avec une masse musculaire diminuée reste donc important [97,112].

\subsubsection{Influences hormonales}

In vitro, la production de cystatine $C$ par des cellules HeLa en culture a été décrite dès 1995 comme transcriptionnellement stimulée par les corticoïdes [113]. En réponse à ces études in vitro, les observations cliniques ne sont pas concordantes. Chez des enfants atteints de syndrome néphrotique traité par des doses élevées de corticoïdes, aucune augmentation des concentrations sériques de cystatine C n'a été retrouvée [114]. En revanche, chez des patients transplantés rénaux et asthmatiques, une augmentation des concentrations de cystatine $\mathrm{C}$ dépendante des doses de corticoïdes a été décrite $[115,116]$. Si l'existence d'un " effet corticoïde " est aujourd'hui admise, son impact clinique sur l'évaluation du DFG reste incertain.

L'hyperthyroïdie augmente les concentrations sériques de cystatine C $[117,118]$. Sachant que la production de cystatine C et le DFG varient en sens opposés en réponse aux hormones thyroïdiennes, l'utilisation de ce marqueur semble inadaptée dans les dysthyroïdies.

\subsubsection{Autres}

Si l'on a cru que la production de cystatine C était indépendante de l'inflammation [119], il semble acquis désormais que l'interleukine 6 (IL-6) induit une augmentation de son expression, au moins dans les cellules dendritiques [120]. Récemment, cette relation a été également suggérée en clinique devant l'observation de concentrations plus élevées de cystatine $C$ en cas d'augmentation de la protéine $C$ réactive (C reactive protein, CRP) [121]. De la même manière, le diabète semble être associé avec des valeurs plus élevées de cystatine C [121]. L'influence du tabagisme et de la consommation d'alcool a également été retrouvée dans certaines études et mériterait d'être évaluée comme facteur de variabilité de la cystatine C [105,122,123].

Au total, la cystatine C n'est pas un marqueur parfait du DFG au sens strict du terme. En effet, si son devenir rénal correspond à celui d'un marqueur endogène du DFG idéal, sa production semble dépendante de facteurs physiologiques, hormonaux et anthropométriques. Toutefois, en comparaison à la créatinine, la concentration sérique de cystatine $C$ semble être globalement un reflet plus fidèle du DFG, notamment pour dépister les formes débutantes d'insuffisance rénale. La cystatine $C$ se positionne actuellement comme un marqueur potentiellement intéressant pour l'estimation du DFG.

\subsection{Considérations analytiques}

Actuellement, à l'exception de méthodes enzyme-linked immunosorbent assay (Elisa) encore insuffisamment validées, les méthodes utilisées pour doser la cystatine $C$ sont basées sur l'agglutination en milieu liquide de particules de latex recouvertes d'anticorps polyclonaux dirigés contre cette protéine. En fonction de la nature du signal mesuré, on distingue la particle-enhanced turbidimetric immuno-assay (PETIA : mesure de la lumière transmise) et la particle-enhanced nephelemetric immuno-assay (PENIA : mesure de la lumière diffusée). La différence technique essentielle entre les deux méthodes réside en le fait que la PETIA peut être effectuée sur un automate multiparamétrique de biochimie (longueur d'onde de 340 à $650 \mathrm{~nm}$ environ en fonction des applications) alors que la PENIA, nécessitant une longueur d'onde infrarouge, ne peut être effectuée que sur un automate dédié à l'immunonéphélémétrie.

La cystatine $C$ humaine recombinante est disponible et il existe actuellement un matériel de référence pouvant faire office d'étalon primaire [124]. Cela est d'autant plus important que les différentes 
méthodes de dosage de cystatine $\mathrm{C}$ ne sont pas strictement superposables et perdent notamment leur linéarité pour des valeurs sériques supérieures à $2 \mathrm{mg} / \mathrm{l}$ [125]. La variabilité analytique de la cystatine $C$ est toutefois multifactorielle et dépend à la fois du type de détection utilisé, de la nature des anticorps, du type d'automates de mesure et de l'origine des calibrants.

Dans ce contexte, il n'est actuellement pas possible d'ériger une des méthodes de mesure de la cystatine $C$ comme méthode de référence. Toutefois, l'application PENIA a été la plus largement évaluée et a été préférentiellement utilisée pour développer des équations d'estimation du DFG basées sur la cystatine C.

\subsection{Estimation du débit de filtration glomérulaire à partir de la concentration sérique de cystatine $C$ : intérêt dans diverses populations}

Par analogie aux formules basées sur la créatinine sérique, de nombreuses équations visant à estimer le DFG à partir des valeurs de concentration sérique de la cystatine $C$ ont été développées (les principales sont répertoriées dans le Tableau 5). En cohérence avec l'identification des différents facteurs extrarénaux influençant la cystatinémie, des formules d'expression différente en fonction des caractéristiques du patient existent $[84,135]$. Certains auteurs ont récemment suggéré l'intérêt d'une formule combinant la créatinine et la cystatine C $[84,129,134,135,139]$.

Certaines formules ont cependant parfois été élaborées à partir d'échantillons trop petits et/ou de populations trop spécifiques. D'autres sont complexes car mettant en œuvre des paramètres supplémentaires autres que biologiques, sans que cela n'apporte d'avantage évident. De manière générale, ces formules n'ont été que très peu validées dans des populations différentes de celles à partir desquelles elles ont été élaborées. L'avantage de ces formules apparaît, aujourd'hui, relativement faible par rapport à la formule MDRD basée sur la créatininémie, l'âge, le sexe et la race, en tout cas en ce qui concerne la population générale. Toutefois, elles pourraient être plus utiles dans certaines sous-populations où les formules basées sur la créatinine se sont révélées particulièrement peu exactes, comme en pédiatrie $[41,134,135,138]$, en transplantation $[41,84,134,135,140]$, en gériatrie ou chez le patient dénutri [97,112].

Plus récemment, des équations intégrant des valeurs standardisées de cystatine $\mathrm{C}$ ont été développées par le consortium CKD-EPI [139]. L'intérêt premier de ces équations est leur reproductibilité et la possibilité qu'elles offrent de pouvoir enfin utiliser " un langage commun " en matière d'estimation du DFG basée sur la cystatine $C$. Les dernières recommandations K/DIGO suggèrent d'utiliser ces nouvelles équations comme test confirmatif d'entrée dans la maladie rénale chronique [141]. Des études démontrant clairement la pertinence clinique de l'utilisation de la cystatine $C$ sont en attente.

\subsubsection{Populations pédiatriques}

Le fait que la cystatine $C$ ne dépende pas, ou en tout cas beaucoup moins, de la masse musculaire est, en pédiatrie, un avantage théorique important sur la créatinine. En effet, les valeurs de référence de la créatinine ne peuvent être considérées qu'en fonction de l'âge du patient [142]. Or, plusieurs auteurs ont démontré que les valeurs de référence de la cystatine $C$ sont identiques (ou très proches) pour les adultes et les enfants de plus de 1 an $[41,143]$. Plusieurs études ont évalué la capacité de la cystatine $C$ à détecter une insuffisance rénale en pédiatrie plus précocement que la créatininémie ou que les formules d'estimation du DFG basées sur la créatinine. Les résultats restent toutefois contradictoires, certains en faveur de la cystatine C [126,144-148], alors que d'autres ne lui reconnaissent aucune valeur ajoutée [149-153]. Cela peut s'expliquer par les limitations inhérentes à l'étude spécifique des enfants (difficulté à la mise en œuvre des techniques de mesure directe du DFG, absence de consensus sur la normalité des valeurs du DFG chez l'enfant) et aussi par le fait que beaucoup d'auteurs n'ont pas dissocié les enfants avec ou sans corticothérapie.

Plusieurs auteurs ont mis au point des formules d'évaluation du DFG basées sur la cystatine $C$, parfois couplée à la créatinine. Les formules de Filler et de Grubb ont été construites sur la base de l'étude d'un grand nombre de patients ( $n=536$ pour les deux) $[41,130]$, mais n'ont été que peu validées dans des populations pédiatriques autres que celles où elles ont été élaborées [154]. Une étude récente et méthodologiquement solide et publiée par Schwartz a démontré également une valeur ajoutée significative de la cystatine $C$, en combinaison avec la créatinine, pour l'estimation du DFG chez l'enfant [138].

\subsubsection{Intérêt de la cystatine $C$ en transplantation}

Globalement, les équations intégrant la cystatine $C$ semblent apporter une meilleure performance prédictive, même s'il reste encore à démontrer que cette amélioration de prédiction soit cliniquement substantielle [155]. En transplantation cardiaque, l'équation de Rule et al. intégrant la cystatine $C$ permet d'augmenter significativement la justesse de prédiction du DFG par rapport à l'équation MDRD [84,156]. Une meilleure performance prédictive des équations basées sur la cystatine $\mathrm{C}$ a également été rapportée en transplantation hépatique [95].

Parmi les différentes équations intégrant la cystatine $C$ et qui ont été testées en transplantation, celle offrant la meilleure estimation du DFG n'est pas toujours la même d'une étude à l'autre. Il est possible que des équations propres aux patients transplantés soient nécessaires. En effet, confirmant des résultats antérieurs qui avaient déjà suggéré une possible sous-estimation du DFG par la cystatine C en transplantation, Rule et al. ont observé que le DFG est supérieur de $19 \%$ chez les patients transplantés par rapport aux patients insuffisants rénaux à reins natifs [84]. L'explication la plus communément avancée est celle d'une production accrue de cystatine $C$ induite par l'utilisation des traitements immunosuppresseurs, notamment les stéroïdes. Cela a conduit certains auteurs à élaborer des équations spécifiquement développées pour des patients transplantés, adultes ou enfants $[84,131,135]$. Les équations de Rule et al. et de Le Bricon et al. sont souvent retrouvées parmi les équations les plus performantes en transplantation. Cependant, la démonstration qu'une équation développée spécifiquement pour la transplantation offre une estimation du DFG significativement meilleure reste encore à faire.

Les dernières équations développées à partir d'une cystatine $C$ standardisée par le CKD-EPI ont été récemment validées chez le transplanté rénal mais avec une valeur ajoutée qui reste modeste sur le plan clinique par rapport à un estimateur basé sur la seule créatininémie [140].

\subsubsection{Patients âgés}

La sarcopénie liée au vieillissement s'accompagne d'une baisse de la production de la créatinine. Les équations prédictives incluant l'âge et le sexe prennent partiellement en compte cette donnée. L'inflammation, la malnutrition et le déconditionnement musculaire (souvent associés aux pathologies chroniques comme l'insuffisance cardiaque ou les bronchopneumopathies) peuvent encore accentuer les anomalies du métabolisme musculaire et affecter la valeur des équations prédictives basées sur la créatinine [69].

Chez le sujet âgé, la cystatine $\mathrm{C}$ paraît moins sensible aux facteurs métaboliques et extrarénaux que la créatinine [157]. La cystatine $C$ pourrait aussi être un marqueur plus sensible que la créatinine pour dépister les altérations modérées du DFG chez le 
Tableau 5

Principales formules d'estimation du débit de filtration glomérulaire (DFG) basées sur la cystatine C plasmatique.

\begin{tabular}{|c|c|c|c|c|c|}
\hline Références & $n$ & $\begin{array}{l}\text { Mesure } \\
\text { du DFG }\end{array}$ & CysC & Population & Formules \\
\hline $\begin{array}{l}\text { Bokenkamp } \\
\text { et al. [126] }\end{array}$ & 83 & Inuline & PETIA & Pédiatrie & $\frac{162}{[\text { cystatine C] }}-30$ \\
\hline Tan et al. [127] & 40 & Iohexol & PENIA & $\begin{array}{l}\text { Diabétiques } \\
\text { et sains }\end{array}$ & $\frac{87,1}{[\text { cystatine C] }}-6,87$ \\
\hline Hoek et al. [128] & 47 & Iothalamate & PENIA & Divers & $\frac{80,35}{[\text { cystatine } C]}-4,32$ \\
\hline \multirow[t]{2}{*}{$\begin{array}{l}\text { Larsson et al. } \\
\text { [129] }\end{array}$} & 100 & Iohexol & PENIA & Divers & $77,24 \times[\text { cystatine } C]^{-1,2623}$ \\
\hline & & & PETIA & & $99,43 \times[\text { cystatine } C]^{-1,5837}$ \\
\hline $\begin{array}{l}\text { Filler et Lepage } \\
\text { [130] }\end{array}$ & 536 & $\left({ }^{99 \mathrm{~m}} \mathrm{Tc}\right)-\mathrm{DTPA}$ & PENIA & Pédiatrie & $91,62 \times\left(\frac{1}{\text { [cystatine C] }}\right)^{1,123}$ \\
\hline $\begin{array}{l}\text { Le Bricon et al. } \\
\text { [131] }\end{array}$ & 25 & $\left({ }^{51} \mathrm{Cr}\right)-\mathrm{EDTA}$ & PENIA & Greffés & $\left(78 \times \frac{1}{[\text { cystatine } C]}\right)+4$ \\
\hline $\begin{array}{l}\text { Sjostrom et al. } \\
\text { [132] }\end{array}$ & 381 & Iohexol & PETIA & Divers & $\frac{124}{[\text { cystatine } C]}-22,3$ \\
\hline Grubb et al. [41] & 536 & Iohexol & PETIA & $\begin{array}{l}\text { Divers }+ \\
\text { pédiatrie } \\
(n=85)\end{array}$ & $84,69 \times[\text { cystatine } C]^{-1,68} \times(1,384$ si moins de 14 ans $)$ \\
\hline Rule et al. [84] & 204 & Iothalamate & PENIA & $\begin{array}{l}\text { Divers sauf } \\
\text { greffés }\end{array}$ & $\begin{array}{l}66,8 \times[\text { cystatine } C]^{-1,3} \\
\left(\left[66,8 \times[\text { cystatine } C]^{-1,3}\right] \times\left[273 \times[\text { créatinine }]^{-1,22} \times \hat{a g g} e^{-0,299} \times(0,738 \text { si femme })\right]\right)^{0,5}\end{array}$ \\
\hline Rule et al. [84] & 206 & & & Greffés & $76,6 \times[\text { cystatine } C]^{-1,16}$ \\
\hline $\begin{array}{l}\text { MacIsaac et al. } \\
\text { [133] }\end{array}$ & 125 & $\left({ }^{99 \mathrm{~m}} \mathrm{Tc}\right)-\mathrm{DTPA}$ & PENIA & Diabétiques & $\frac{84,6}{[\text { cystatine C] }}-3,2$ \\
\hline $\begin{array}{l}\text { Bouvet et al. } \\
\text { [134] }\end{array}$ & 67 & $\left({ }^{51} \mathrm{Cr}\right)-\mathrm{EDTA}$ & PENIA & Pédiatrie & $63,2 \times\left(\frac{[\text { créatinine }]}{96}\right)^{-0,35} \times\left(\frac{[\text { cystatine } C]}{1,2}\right)^{-0,56} \times\left(\frac{\text { poids }}{45}\right)^{0,3} \times\left(\frac{\hat{a g g e}}{14}\right)^{0,4}$ \\
\hline \multirow[t]{2}{*}{$\begin{array}{l}\text { Zappitelli } \\
\text { et al. [135] }\end{array}$} & 103 & Iothalamate & PENIA & Pédiatrie & $\frac{75,94}{[\text { cystatine } C]^{1,17}} \times(1,2$ si greffe rénale $)$ \\
\hline & & & & & $\frac{43,82 \times e^{0,003} \times \text { taille }}{[\text { cystatine } C]^{0,635} \times[\text { créatinine }]^{0,547}}$ \\
\hline Ma et al. [136] & 376 & $\left({ }^{99 \mathrm{~m}} \mathrm{Tc}\right)-\mathrm{DTPA}$ & PENIA & $\begin{array}{l}\text { Divers, } \\
\text { Chinois }\end{array}$ & $169 \times[\text { créatinine }]^{-0,608} \times[\text { cystatine } C]^{-0,63} \times \hat{a g g} e^{-0,157} \times(0,83$ pour sexe féminin $)$ \\
\hline $\begin{array}{l}\text { Stevens et al. } \\
\text { [137] }\end{array}$ & 3418 & $\begin{array}{l}\text { Iothalamate } \\
\text { et }\left({ }^{51} \mathrm{Cr}\right) \text {-EDTA }\end{array}$ & PENIA & $\begin{array}{l}\text { Maladie } \\
\text { rénale } \\
\text { chronique }\end{array}$ & $\begin{array}{l}\text { CKD-EPI-CysC1 }=76,7 \times[\text { cystatine } C]^{-1,19} \\
\text { CKD-EPI-CysC2 }=127,7 \times[\text { cystatine } C]^{1,17} \times \hat{a g g} e^{-0,13} \times(0,91 \text { pour sexe féminin }) \times \\
(1,06 \text { pour Noir Africain }) \\
\text { CKD-EPI mixte }=177,6 \times[\text { créatinine }]^{-0,65} \times[\text { cystatine } C]^{-0,57} \times \hat{a g g} e^{-0,20} \times \\
(0,82 \text { pour sexe féminin }) \times(1,11 \text { pour Noir Africain })\end{array}$ \\
\hline $\begin{array}{l}\text { Schwartz } \\
\text { et al. [138] }\end{array}$ & 965 & Iohexol & PENIA & Pédiatrie & $39,8 \times\left(\frac{\text { taille }}{[\text { créatinine }]}\right)^{0,456} \times\left(\frac{1,8}{\text { [cystatine C] }}\right)^{0,418} \times\left(\frac{30}{[\text { urée }]}\right)^{0,079} \times(1,076$ si homme $) \times\left(\frac{\text { taille }}{1,4}\right)^{0,179}$ \\
\hline $\begin{array}{l}\text { CKD-EPI } \\
\text { combinée [139] }\end{array}$ & 5352 & Iothalamate & PENIA & $\begin{array}{l}\text { Adultes, } \\
\text { tous } \\
\text { niveaux } \\
\text { de DFG }\end{array}$ & $\begin{array}{l}A \times\left(\frac{[\text { créatinine }]}{B}\right)^{C} \times\left(\frac{[\text { cystatine } C]}{0,8}\right)^{D} \times 0,995^{\hat{a} g e} \times(1,08 \text { si Noir Africain }) \\
\text { Avec : } \\
A=130 \text { si femme } ; 135 \text { si homme } \\
B=0,7 \text { si femme } ; 0,9 \text { si homme } \\
C=-0,248 \text { si femme et }[\text { créatinine }] \leq 0,7 ;-0,601 \text { si femme et }[\text { créatinine }]>0,7 \text { ou si } \\
\text { homme et [créatinine] }>0,9 ;-0,207 \text { si homme et [créatinine] } \leq 0,9 \\
D=-0,375 \text { si [cystatine } C] \leq 0,8 ;-0,711 \text { si }[\text { cystatine } C]>0,8\end{array}$ \\
\hline BIS combinée [16] & 570 & Iohexol & PENIA & $\begin{array}{l}\text { Âgés de plus } \\
\text { de } 70 \text { ans }\end{array}$ & $767 \times[\text { cystatine } C]^{-0,61} \times[\text { créatinine }]^{-0,40} \times \hat{a g} e^{-0,57} \times(0,87$ pour sexe féminin $)$ \\
\hline
\end{tabular}

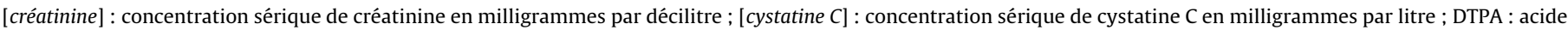

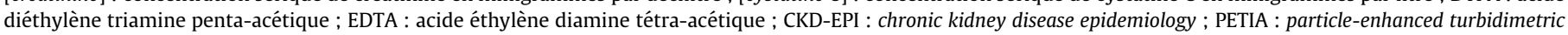

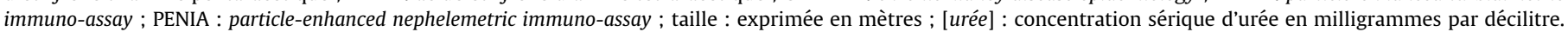

sujet âgé (69 à 92 ans) [158,159], même si des résultats non ou peu concluants ont aussi été rapportés [71,73,160]. Plus récemment, la BIS qui s'est intéressée (avec une méthodologie très robuste) à l'estimation du DFG spécifiquement chez la personne âgée a rapporté une meilleure performance des équations intégrant la cystatine $\mathrm{C}$ par rapport à celles intégrant uniquement la créatininémie [16].

\section{Conclusions et perspectives}

La variable biologique "DFG » est plus qu'un simple marqueur de la fonction rénale : il constitue la pierre angulaire du système de classification internationale de la maladie rénale chronique $[17,24]$; un DFG altéré est maintenant identifié comme un facteur majeur et indépendant de risque cardiovasculaire [161]. 
Tout naturellement, la question de l'évaluation du DFG est revenue ces dernières années au premier plan des préoccupations de la communauté néphrologique. À cet égard, il faut saluer la contribution du consortium CKD-EPI [5]. Ce groupe de recherche, formé à l'initiative d'Andrew S. Levey (Tufts-New England Medical Center), s'est fixé pour objectif de développer et valider de nouvelles équations d'estimation du DFG à partir d'un ensemble de données cliniques et biologiques extraites de différentes études cliniques qui ont en commun d'une part, de disposer d'une mesure directe du DFG [dans la majorité des cas, il s'agit d'une clairance urinaire au $\left({ }^{125} \mathrm{I}\right)$-iothalamate] et d'autre part, de pouvoir calibrer la mesure de créatinine plasmatique sur la méthode de référence IDMS. Au-delà de la production de nouveaux estimateurs du DFG (au premier rang desquels, bien sûr, les équations MDRD et CKDEPI), les travaux du groupe CKD-EPI ont permis d'identifier plusieurs obstacles à une évaluation fiable du DFG. Parmi ceuxci, nous avons évoqué les difficultés analytiques liées au dosage de la créatinine (qui sont en partie corrigées par le raccordement des méthodes de dosage au standard IDMS), les limitations physiologiques inhérentes à l'utilisation même de la créatinine comme marqueur du DFG (qui reste un marqueur loin d'être idéal dans de nombreuses populations), la difficulté à évaluer précisément une altération modérée du DFG (qui se répercute sur le dépistage de la maladie rénale chronique). Il n'en reste pas moins qu'actuellement il existe un consensus autour de l'équation CKD-EPI qui a véritablement supplanté la formule de Cockcroft et Gault [12]. Les nouvelles équations CKD-EPI basées sur la cystatine $C$ améliorent, certes, l'estimation mais de manière encore trop limitée en regard du surcoût. Ce point doit être néanmoins relativisé tant il est probable qu'une plus large utilisation de la cystatine $C$ en pratique clinique s'accompagnerait d'une réduction substantielle de la tarification de son dosage.

- L'équation CKD-EPI est actuellement l'estimateur du DFG de référence, basé sur la créatinine plasmatique. La cystatine $C$ est un marqueur endogène de filtration glomérulaire potentiellement plus fiable que la créatinine.

Les équations d'estimation du DFG ne peuvent pas remplacer les méthodes de mesure directe du DFG lorsqu'une évaluation précise de la fonction rénale est indispensable.

\section{Déclaration d'intérêts}

Les auteurs déclarent ne pas avoir de conflits d'intérêts en relation avec cet article.

\section{Références}

[1] Cockcroft DW, Gault MH. Prediction of creatinine clearance from serum creatinine. Nephron 1976;16:31-41.

[2] Levey AS, Bosch JP, Lewis JB, Greene T, Rogers N, Roth D. A more accurate method to estimate glomerular filtration rate from serum creatinine: a new prediction equation. Modification of Diet in Renal Disease Study Group. Ann Intern Med 1999:130:461-70.

[3] Levey AS, Coresh J, Greene T, Stevens LA, Zhang YL, Hendriksen S, et al. Using standardized serum creatinine values in the modification of diet in renal disease study equation for estimating glomerular filtration rate. Ann Intern Med 2006;145:247-54

[4] Levey AS, Stevens LA, Schmid CH, Zhang YL, Castro III AF, Feldman HI, et al. A new equation to estimate glomerular filtration rate. Ann Intern Med 2009;150:604-12.

[5] Bjornsson TD, Cocchetto DM, McGowan FX, Verghese CP, Sedor F. Nomogram for estimating creatinine clearance. Clin Pharmacokinet 1983;8:365-9.

[6] Davis GA, Chandler MH. Comparison of creatinine clearance estimation methods in patients with trauma. Am J Health Syst Pharm 1996;53:1028-32.
[7] Edwards KD, Whyte HM. Plasma creatinine level and creatinine clearance as tests of renal function. Australas Ann Med 1959;8:218-24.

[8] Gates GF. Creatinine clearance estimation from serum creatinine values: an analysis of three mathematical models of glomerular function. Am J Kidney Dis 1985:5:199-205.

[9] Hull JH, Hak LJ, Koch GG, Wargin WA, Chi SL, Mattocks AM. Influence of range of renal function and liver disease on predictability of creatinine clearance. Clin Pharmacol Ther 1981;29:516-21.

[10] Jelliffe RW. Letter: Creatinine clearance: bedside estimate. Ann Intern Med 1973;79:604-5.

[11] Mawer GE, Lucas SB, Knowles BR, Stirland RM. Computer-assisted prescribing of kanamycin for patients with renal insufficiency. Lancet 1972;1:12-5.

[12] Nankivell BJ, Gruenewald SM, Allen RD, Chapman JR. Predicting glomerular filtration rate after kidney transplantation. Transplantation 1995;59:1683-9.

[13] Walser M, Drew HH, Guldan JL. Prediction of glomerular filtration rate from serum creatinine concentration in advanced chronic renal failure. Kidney Int $1993 ; 44: 1145-8$

[14] Rule AD, Larson TS, Bergstralh EJ, Slezak JM, Jacobsen SJ, Cosio FG. Using serum creatinine to estimate glomerular filtration rate: accuracy in good health and in chronic kidney disease. Ann Intern Med 2004;141:929-37.

[15] Salazar DE, Corcoran GB. Predicting creatinine clearance and renal drug clearance in obese patients from estimated fat-free body mass. Am J Med 1988:84:1053-60.

[16] Schaeffner ES, Ebert N, Delanaye P, Frei U, Gaedeke J, Jakob O, et al. Two novel equations to estimate kidney function in persons aged 70 years or older. Ann Intern Med 2012;157:471-81

[17] National Kidney Foundation. K/DOQI clinical practice guidelines for chronic kidney disease: evaluation, classification, and stratification. Am J Kidney Dis 2002;39:S1-266.

[18] Levey AS, Greene T, Kusek J, Beck G. A simplified equation to predict glomerular filtration rate from serum creatinine. J Am Soc Nephrol 2000;11(155A) [abstract].

[19] Pieroni L, Delanaye P, Boutten A, Bargnoux AS, Rozet E, Delatour V, et al. A multicentric evaluation of IDMS-traceable creatinine enzymatic assays. Clin Chim Acta 2011;412:2070-5.

[20] Van Biesen W, Vanholder R, Veys N, Verbeke F, Delanghe J, de Bacquer D, et al. The importance of standardization of creatinine in the implementation of guidelines and recommendations for CKD: implications for CKD management programmes. Nephrol Dial Transplant 2005;21:77-83.

[21] Bland JM, Altman DG. Statistical methods for assessing agreement between two methods of clinical measurement. Lancet 1986;1:307-10.

[22] Coresh J, Selvin E, Stevens LA, Manzi J, Kusek JW, Eggers P, et al. Prevalence of chronic kidney disease in the United States. JAMA 2007;298:2038-47.

[23] Delanaye P, Cohen EP. Formula-based estimates of the GFR: equations variable and uncertain. Nephron Clin Pract 2008;110:c48-53.

[24] Anon.. KDIGO 2012 Clinical Practice Guideline for the Evaluation and Management of Chronic Kidney Disease. Kidney Int Suppl 2013;3:1-150.

[25] Blake GM, Sibley-Allen C, Hilton R, Burnapp L, Moghul MR, Goldsmith D. Glomerular filtration rate in prospective living kidney donors. Int Urol Nephrol 2013;45:1445-52

[26] Davies DF, Shock NW. Age changes in glomerular filtration rate, effective renal plasma flow, and tubular excretory capacity in adult males. J Clin Invest 1950;29:496-507

[27] Delanaye P, Schaeffner E, Ebert N, Cavalier E, Mariat C, Krzesinski JM, et al Normal reference values for glomerular filtration rate: what do we really know? Nephrol Dial Transplant 2012;27:2664-72.

[28] Poggio ED, Rule AD, Tanchanco R, Arrigain S, Butler RS, Srinivas T, et al. Demographic and clinical characteristics associated with glomerular filtration rates in living kidney donors. Kidney Int 2009;75:1079-87.

[29] van den Brand JA, van Boekel GA, Willems HL, Kiemeney LA, den HM, Wetzels JF. Introduction of the CKD-EPI equation to estimate glomerular filtration rate in a Caucasian population. Nephrol Dial Transplant 2011;26:3176-81.

[30] Glassock RJ, Winearls C. An epidemic of chronic kidney disease: fact or fiction? Nephrol Dial Transplant 2008;23:1117-21.

[31] Glassock RJ, Winearls CG. eGFR: Readjusting its rating. Clin J Am Soc Nephrol 2009;4:867-9.

[32] Lewis J, Agodoa L, Cheek D, Greene T, Middleton J, O’Connor D, et al Comparison of cross-sectional renal function measurements in African Americans with hypertensive nephrosclerosis and of primary formulas to estimate glomerular filtration rate. Am J Kidney Dis 2001;38:744-53.

[33] Bostom AG, Kronenberg F, Ritz E. Predictive performance of renal function equations for patients with chronic kidney disease and normal serum creatinine levels. J Am Soc Nephrol 2002;13:2140-4.

[34] Lin J, Knight EL, Hogan ML, Singh AK. A Comparison of Prediction Equations for Estimating Glomerular Filtration Rate in Adults without Kidney Disease. J Am Soc Nephrol 2003;14:2573-80.

[35] Hallan S, Asberg A, Lindberg M, Johnsen H. Validation of the Modification of Diet in Renal Disease formula for estimating GFR with special emphasis on calibration of the serum creatinine assay. Am J Kidney Dis 2004:44:84-93.

[36] Rule AD, Gussak HM, Pond GR, Bergstralh EJ, Stegall MD, Cosio FG, et al. Measured and estimated GFR in healthy potential kidney donors. Am J Kidney Dis 2004;43:112-9.

[37] Poggio ED, Wang X, Greene T, Van Lente F, Hall PM. Performance of the modification of diet in renal disease and Cockcroft-Gault equations in the estimation of GFR in health and in chronic kidney disease. J Am Soc Nephrol 2005;16:459-66. 
[38] Poggio ED, Nef PC, Wang X, Greene T, Van Lente F, Dennis VW, et al. Performance of the Cockcroft-Gault and modification of diet in renal disease equations in estimating GFR in ill hospitalized patients. Am J Kidney Dis $2005 ; 46: 242-52$.

[39] Ibrahim H, Mondress M, Tello A, Fan Y, Koopmeiners J, Thomas W. An alternative formula to the Cockcroft-Gault and the modification of diet in renal diseases formulas in predicting GFR in individuals with type 1 diabetes. J Am Soc Nephrol 2005;16:1051-60.

[40] Cirillo M, Anastasio P, De Santo NG. Relationship of gender, age, and body mass index to errors in predicted kidney function. Nephrol Dial Transplant $2005 ; 20: 1791-8$

[41] Grubb A, Nyman U, Bjork J, Lindstrom V, Rippe B, Sterner G, et al. Simple cystatin C-based prediction equations for glomerular filtration rate compared with the modification of diet in renal disease prediction equation for adults and the Schwartz and the Counahan-Barratt prediction equations for children. Clin Chem 2005:51:1420-31.

[42] Rigalleau V, Lasseur C, Perlemoine C, Barthe N, Raffaitin C, Liu C, et al. Estimation of glomerular filtration rate in diabetic subjects: Cockcroft formula or modification of Diet in Renal Disease study equation? Diabetes Care 2005;28:838-43.

[43] Froissart M, Rossert J, Jacquot C, Paillard M, Houillier P. Predictive performance of the modification of diet in renal disease and Cockcroft-Gault equations for estimating renal function. J Am Soc Nephrol 2005;16:763-73.

[44] Verhave JC, Fesler P, Ribstein J, du CG, Mimran A. Estimation of renal function in subjects with normal serum creatinine levels: influence of age and body mass index. Am J Kidney Dis 2005;46:233-41.

[45] Murata K, Baumann NA, Saenger AK, Larson TS, Rule AD, Lieske JC. Relative Performance of the MDRD and CKD-EPI Equations for Estimating Glomerular Filtration Rate among Patients with Varied Clinical Presentations. Clin J Am Soc Nephrol 2011:6:1963-72.

[46] Eriksen BO, Mathisen UD, Melsom T, Ingebretsen OC, Jenssen TG, Njolstad I, et al. Cystatin $C$ is not a better estimator of GFR than plasma creatinine in the general population. Kidney Int 2010;78:1305-11.

[47] Bjork J, Jones I, Nyman U, Sjostrom P. Validation of the Lund-Malmo. Chronic Kidney Disease Epidemiology (CKD-EPI) and Modification of Diet in Renal Disease (MDRD) equations to estimate glomerular filtration rate in a large Swedish clinical population. Scand J Urol Nephrol 2012;46:212-22.

[48] Buron F, Hadj-Aissa A, Dubourg L, Morelon E, Steghens JP, Ducher M, et al Estimating glomerular filtration rate in kidney transplant recipients: performance over time of four creatinine-based formulas. Transplantation 2011; 92:1005-11.

[49] Nyman U, Grubb A, Sterner G, Bjork J. The CKD-EPI and MDRD equations to estimate GFR. Validation in the Swedish Lund-Malmo Study cohort. Scand J Clin Lab Invest 2011:71:129-38.

[50] Iliadis F, Didangelos T, Ntemka A, Makedou A, Moralidis E, Gotzamani-Psarakou A, et al. Glomerular filtration rate estimation in patients with type 2 diabetes: creatinine- or cystatin C-based equations? Diabetologia 2011;54:2987-94.

[51] Lane BR, Demirjian S, Weight CJ, Larson BT, Poggio ED, Campbell SC. Performance of the chronic kidney disease-epidemiology study equations for estimating glomerular filtration rate before and after nephrectomy. J Uro 2010:183:896-901.

[52] Cirillo M, Lombardi C, Luciano MG, Bilancio G, Anastasio P, De Santo NG Estimation of GFR: a comparison of new and established equations. Am J Kidney Dis 2010;56:802-4.

[53] Michels WM, Grootendorst DC, Verduijn M, Elliott EG, Dekker FW, Krediet RT. Performance of the Cockcroft-Gault, MDRD, and new CKD-EPI formulas in relation to GFR, age, and body size. Clin J Am Soc Nephrol 2010;5:1003-9.

[54] Tent H, Rook M, Stevens LA, van Son WJ, van Pelt LJ, Hofker HS, et al. Rena function equations before and after living kidney donation: a within-individual comparison of performance at different levels of renal function. Clin Am Soc Nephrol 2010;5:1960-8.

[55] Teo BW, Xu H, Wang D, Li J, Sinha AK, Shuter B, et al. GFR estimating equations in a multiethnic Asian population. Am J Kidney Dis 2011;58:56-63.

[56] White CA, Akbari A, Doucette S, Fergusson D, Knoll GA. Estimating glomerular filtration rate in kidney transplantation: is the new chronic kidney disease epidemiology collaboration equation any better? Clin Chem 2010;56:474-7.

[57] Redal-Baigorri B, Stokholm KH, Rasmussen K, Jeppesen N. Estimation of kidney function in cancer patients. Dan Med Bull 2011;58:A4236.

[58] Poge U, Gerhardt T, Stoffel-Wagner B, Sauerbruch T, Woitas RP. Validation of the CKD-EPI formula in patients after renal transplantation. Nephrol Dial Transplant 2011;26:4104-8.

[59] Jones GR. Use of the CKD-EPI equation for estimation of GFR in an Australian cohort. Pathology 2010;42:487-8.

[60] Kukla A, El-Shahawi Y, Leister E, Kasiske B, Mauer M, Matas A, et al. GFRestimating models in kidney transplant recipients on a steroid-free regimen. Nephrol Dial Transplant 2010;25:1653-61.

[61] Silveiro SP, Araujo GN, Ferreira MN, Souza FD, Yamaguchi HM, Camargo EG. Chronic Kidney Disease Epidemiology Collaboration (CKD-EPI) equation pronouncedly underestimates glomerular filtration rate in type 2 diabetes. Diabetes Care 2011;34:2353-5.

[62] Orskov B, Borresen ML, Feldt-Rasmussen B, Ostergaard O, Laursen I, Strandgaard S. Estimating glomerular filtration rate using the new CKD-EPI equation and other equations in patients with autosomal dominant polycystic kidney disease. Am J Nephrol 2010;31:53-7.

[63] Praditpornsilpa K, Townamchai N, Chaiwatanarat T, Tiranathanagul K, Katawatin P, Susantitaphong P, et al. The need for robust validation for MDRD-based glomerular filtration rate estimation in various CKD populations. Nephrol Dial Transplant 2011:26:2780-5.

[64] Froissart MC, Rossert J, Houillier P. The new Mayo Clinic equation for estimating glomerular filtration rate. Ann Intern Med 2005;142:679.

[65] Srinivas S, Annigeri RA, Mani MK, Rao BS, Kowdle PC, Seshadri R. Estimation of glomerular filtration rate in South Asian healthy adult kidney donors. Nephrology (Carlton) 2008;13:440-6.

[66] Delanaye P, Pottel H, Botev R. Con: Should we abandon the use of the MDRD equation in favour of the CKD-EPI equation? Nephrol Dial Transplant 2013; 28:1396-403

[67] Delanaye P, Mariat C, Moranne O, Cavalier E, Flamant M. L'estimation du débit de filtration glomérulaire en 2012 : quelle valeur ajoutée pour la nouvelle équation CKD-EPI ? Nephrol Ther 2012;8:199-205.

[68] Earley A, Miskulin D, Lamb EJ, Levey AS, Uhlig K. Estimating equations for glomerular filtration rate in the era of creatinine standardization: a systematic review. Ann Intern Med 2012:156:785-95.

[69] Froissart M, Rossert J. Comment estimer la fonction rénale chez le sujet âgé ? Rev Prat 2005;55:2223-9.

[70] Lamb EJ, Wood J, Stowe HJ, O'Riordan SE, Webb MC, Dalton RN. Susceptibility of glomerular filtration rate estimations to variations in creatinine methodology: a study in older patients. Ann Clin Biochem 2005;42:11-8.

[71] Van Den Noortgate NJ, Janssens WH, Delanghe JR, Afschrift MB, Lameire NH. Serum cystatin $C$ concentration compared with other markers of glomerular filtration rate in the old old. J Am Geriatr Soc 2002;50:1278-82.

[72] Flamant M, Haymann JP, Vidal-Petiot E, Letavernier E, Clerici C, Boffa JJ, et al. GFR Estimation Using the Cockcroft-Gault, MDRD Study, and CKD-EPI Equations in the Elderly. Am J Kidney Dis 2012;60:847-9.

[73] Kilbride HS, Stevens PE, Eaglestone G, Knight S, Carter JL, Delaney MP, et al. Accuracy of the MDRD (Modification of Diet in Renal Disease) study and CKDEPI (CKD Epidemiology Collaboration) equations for estimation of GFR in the elderly. Am J Kidney Dis 2013;61:57-66.

[74] Delanaye P, Mariat C, Cavalier E, Krzesinski JM. Indexation du débit de filtration glomérulaire par la surface corporelle : mythe et réalité. Nephrol Ther 2009;5:614-22.

[75] Delanaye P, Mariat C, Cavalier E, Krzesinski JM. Errors induced by indexing glomerular filtration rate for body surface area: reductio ad absurdum. Nephrol Dial Transplant 2009;24:3593-6.

[76] Bouquegneau A, Vidal-Petiot E, Vrtovsnik F, Cavalier E, Rorive M, Krzesinski JM, et al. Modification of Diet in Renal Disease versus Chronic Kidney Disease Epidemiology Collaboration equation to estimate glomerular filtration rate in obese patients. Nephrol Dial Transplant 2013;28(Suppl. 4):iv122-30.

[77] Stevens LA, Claybon MA, Schmid CH, Chen J, Horio M, Imai E, et al. Evaluation of the Chronic Kidney Disease Epidemiology Collaboration equation for estimating the glomerular filtration rate in multiple ethnicities. Kidney Int 2011;79:555-62

[78] Imai E, Horio M, Nitta K, Yamagata K, Iseki K, Tsukamoto Y, et al. Modification of the Modification of Diet in Renal Disease (MDRD) Study equation for Japan. Am J Kidney Dis 2007:50:927-37.

[79] Ma YC, Zuo L, Chen JH, Luo Q, Yu XQ, Li Y, et al. Modified glomerular filtration rate estimating equation for Chinese patients with chronic kidney disease. J Am Soc Nephrol 2006;17:2937-44.

[80] Horio M, Imai E, Yasuda Y, Watanabe T, Matsuo S. Modification of the CKD epidemiology collaboration (CKD-EPI) equation for Japanese: accuracy and use for population estimates. Am J Kidney Dis 2010;56:32-8.

[81] Mariat C, Alamartine E, Afiani A, Thibaudin L, Laurent B, Berthoux P, et al. Predicting glomerular filtration rate in kidney transplantation: are the K/ DOQI guidelines applicable? Am J Transplant 2005;5:2698-703.

[82] Bosma RJ, Doorenbos CR, Stegeman CA, van der Heide JJ, Navis G. Predictive performance of renal function equations in renal transplant recipients: an analysis of patient factors in bias. Am J Transplant 2005;5:2193-203.

[83] Gaspari F, Ferrari S, Stucchi N, Centemeri E, Carrara F, Pellegrino M, et al. Performance of different prediction equations for estimating renal function in kidney transplantation. Am J Transplant 2004;4:1826-35.

[84] Rule AD, Bergstralh EJ, Slezak JM, Bergert J, Larson TS. Glomerular filtration rate estimated by cystatin $\mathrm{C}$ among different clinical presentations. Kidney Int 2006;69:399-405

[85] Raju DL, Grover VK, Shoker A. Limitations of glomerular filtration rate equations in the renal transplant patient. Clin Transplant 2005;19:259-68.

[86] Poge U, Gerhardt T, Palmedo H, Klehr HU, Sauerbruch T, Woitas RP. MDRD equations for estimation of GFR in renal transplant recipients. Am J Transplant 2005;5:1306-11.

[87] Poge U, Gerhardt T, Stoffel-Wagner B, Palmedo $H$, Klehr HU, Sauerbruch T, et al. Prediction of glomerular filtration rate in renal transplant recipients: cystatin C or modification of diet in renal disease equation? Clin Transplant 2006;20:200-5

[88] Poggio ED, Wang X, Weinstein DM, Issa N, Dennis VW, Braun WE, et al. Assessing glomerular filtration rate by estimation equations in kidney transplant recipients. Am J Transplant 2006;6:100-8

[89] White C, Akbari A, Hussain N, Dinh L, Filler G, Lepage N, et al. Estimating glomerular filtration rate in kidney transplantation: a comparison between serum creatinine and cystatin C-based methods. J Am Soc Nephrol 2005;16: 3763-70.

[90] Maillard N, Mariat C, Bonneau C, Mehdi M, Thibaudin L, Laporte S, et al. Cystatin C-based equations in renal transplantation: moving toward a better glomerular filtration rate prediction? Transplantation 2008;85: $1855-8$. 
[91] Masson I, Flamant M, Maillard N, Rule AD, Vrtovsnik F, Peraldi MN, et al. MDRD versus CKD-EPI equation to estimate glomerular filtration rate in kidney transplant recipients. Transplantation 2013;95:1211-7.

[92] Bargnoux AS, Servel AC, Pieroni L, Dupuy AM, Badiou S, Garrigue V, et al. Accuracy of GFR predictive equations in renal transplantation: Validation of a new turbidimetric cystatin C assay on Architect c8000(R). Clin Biochem 2012;45:151-3

[93] Maillard N, Alamartine E, Berthoux F, Delanaye P, Mariat C. On the demanding necessity of properly evaluating renal graft function in clinical trials. Transpl Int 2009;22:247-8.

[94] Delanaye P, Nellessen E, Grosch S, Depas G, Cavalier E, Defraigne JO, et al. Creatinine-based formulae for the estimation of glomerular filtration rate in heart transplant recipients. Clin Transplant 2006;20:596-603.

[95] Gerhardt T, Poge U, Stoffel-Wagner B, Ahrendt M, Wolff M, Spengler U, et al. Estimation of glomerular filtration rates after orthotopic liver transplantation: Evaluation of cystatin C-based equations. Liver Transpl 2006;12: $1667-72$.

[96] Gonwa TA, Jennings L, Mai ML, Stark PC, Levey AS, Klintmalm GB. Estimation of glomerular filtration rates before and after orthotopic liver transplantation: evaluation of current equations. Liver Transpl 2004;10:301-9.

[97] Segarra A, de la Torre J, Ramos N, Quiroz A, Garjau M, Torres I, et al. Assessing glomerular filtration rate in hospitalized patients: a comparison between CKD-EPI and four cystatin C-based equations. Clin J Am Soc Nephrol 2011;6: 2411-20.

[98] Simonsen O, Grubb A, Thysell H. The blood serum concentration of cystatin C (gamma-trace) as a measure of the glomerular filtration rate. Scand J Clin Lab Invest 1985;45:97-101.

[99] Tenstad O, Roald AB, Grubb A, Aukland K. Renal handling of radiolabelled human cystatin C in the rat. Scand J Clin Lab Invest 1996;56:409-14

[100] Jacobsson B, Lignelid H, Bergerheim US. Transthyretin and cystatin C are catabolized in proximal tubular epithelial cells and the proteins are not useful as markers for renal cell carcinomas. Histopathology 1995;26:559-64.

[101] Kaseda R, Iino N, Hosojima M, Takeda T, Hosaka K, Kobayashi A, et al. Megalin-mediated endocytosis of cystatin C in proximal tubule cells. Biochem Biophys Res Commun 2007;357:1130-4.

[102] van Rossum LK, Zietse R, Vulto AG, de Rijke YB. Renal extraction of cystatin C vs 125I-iothalamate in hypertensive patients. Nephrol Dial Transplant 2006;21:1253-6.

[103] Delanaye P, Cavalier E, Chapelle JP, Krzesinski JM, Froissart M. Renal extraction of cystatin C. Nephrol Dial Transplant 2006;21:3333.

[104] Grubb AO. Cystatin C - properties and use as diagnostic marker. Adv Clin Chem 2000;35:63-99.

[105] Galteau MM, Guyon M, Gueguen R, Siest G. Determination of serum cystatin C: biological variation and reference values. Clin Chem Lab Med 2001;39:850-7.

[106] Knight EL, Verhave JC, Spiegelman D, Hillege HL, de Zeeuw D, Curhan GC, et al. Factors influencing serum cystatin $C$ levels other than renal function and the impact on renal function measurement. Kidney Int 2004;65:1416-21.

[107] Finney H, Newman DJ, Thakkar H, Fell JM, Price CP. Reference ranges for plasma cystatin $C$ and creatinine measurements in premature infants, neonates, and older children. Arch Dis Child 2000;82:71-5.

[108] Finney H, Newman DJ, Price CP. Adult reference ranges for serum cystatin C, creatinine and predicted creatinine clearance. Ann Clin Biochem 2000;37(Pt 1):49-59.

[109] Perrone RD, Madias NE, Levey AS. Serum creatinine as an index of renal function: new insights into old concepts. Clin Chem 1992;38:1933-53.

[110] Vinge E, Lindergard B, Nilsson-Ehle P, Grubb A. Relationships among serum cystatin C, serum creatinine, lean tissue mass and glomerular filtration rate in healthy adults. Scand J Clin Lab Invest 1999;59:587-92.

[111] Macdonald J, Marcora S, Jibani M, Roberts G, Kumwenda M, Glover R, et al. GFR estimation using cystatin $\mathrm{C}$ is not independent of body composition. Am J Kidney Dis 2006;48:712-9.

[112] Delanaye P, Cavalier E, Radermecker RP, Paquot N, Depas G, Chapelle JP, et al. Cystatin C or Creatinine for Detection of Stage 3 Chronic Kidney Disease in Anorexia Nervosa. Nephron Clin Pract 2008;110:c158-63.

[113] Bjarnadottir M, Grubb A, Olafsson I. Promoter-mediated, dexamethasoneinduced increase in cystatin C production by HeLa cells. Scand J Clin Lab Invest 1995;55:617-23.

[114] Bokenkamp A, van Wijk JA, Lentze MJ, Stoffel-Wagner B. Effect of corticosteroid therapy on serum cystatin $C$ and beta2-microglobulin concentrations. Clin Chem 2002;48:1123-6.

[115] Cimerman N, Brguljan PM, Krasovec M, Suskovic S, Kos J. Serum cystatin C, a potent inhibitor of cysteine proteinases, is elevated in asthmatic patients. Clin Chim Acta 2000;300:83-95.

[116] Risch L, Herklotz R, Blumberg A, Huber AR. Effects of glucocorticoid immunosuppression on serum cystatin $C$ concentrations in renal transplant patients. Clin Chem 2001;47:2055-9.

[117] den Hollander JG, Wulkan RW, Mantel MJ, Berghout A. Is cystatin C a marker of glomerular filtration rate in thyroid dysfunction? Clin Chem 2003;49:1558-9.

[118] Wiesli P, Schwegler B, Spinas GA, Schmid C. Serum cystatin C is sensitive to small changes in thyroid function. Clin Chim Acta 2003;338:87-90.

[119] Randers E, Kornerup K, Erlandsen EJ, Hasling C, Danielsen H. Cystatin C levels in sera of patients with acute infectious diseases with high C-reactive protein levels. Scand J Clin Lab Invest 2001;61:333-5.

[120] Kitamura H, Kamon H, Sawa S, Park SJ, Katunuma N, Ishihara K, et al. IL-6STAT3 controls intracellular MHC class II alphabeta dimer level through cathepsin S activity in dendritic cells. Immunity 2005;23:491-502.
[121] Stevens LA, Schmid CH, Greene T, Li L, Beck GJ, Joffe MM, et al. Factors other than glomerular filtration rate affect serum cystatin $C$ levels. Kidney Int 2009;75:652-60.

[122] Ichihara K, Saito K, Itoh Y. Sources of variation and reference intervals for serum cystatin $C$ in a healthy Japanese adult population. Clin Chem Lab Med 2007; 45:1232-6.

[123] Knight DR, Trainer TD. Negligible effect of bilirubin on serum creatinine measurement by the kinetic Jaffé method. Clin Chem 1978;24:1851-2.

[124] Grubb A, Blirup-Jensen S, Lindstrom V, Schmidt C, Althaus H, Zegers I. First certified reference material for cystatin $C$ in human serum ERM-DA471/IFCC. Clin Chem Lab Med 2010;48:1619-21.

[125] Delanaye P, Pieroni L, Abshoff C, Lutteri L, Chapelle JP, Krzesinski JM, et al. Analytical study of three cystatin C assays and their impact on cystatin C based GFR-prediction equations. Clin Chim Acta 2008;398:118-24.

[126] Bokenkamp A, Domanetzki M, Zinck R, Schumann G, Byrd D, Brodehl J. Cystatin $\mathrm{C}$ - a new marker of glomerular filtration rate in children independent of age and height. Pediatrics 1998;101:875-81.

[127] Tan GD, Lewis AV, James TJ, Altmann P, Taylor RP, Levy JC. Clinical usefulness of cystatin $C$ for the estimation of glomerular filtration rate in type 1 diabetes: reproducibility and accuracy compared with standard measures and iohexol clearance. Diabetes Care 2002;25:2004-9.

[128] Hoek FJ, Kemperman FA, Krediet RT. A comparison between cystatin C, plasma creatinine and the Cockcroft and Gault formula for the estimation of glomerular filtration rate. Nephrol Dial Transplant 2003;18:2024-31.

[129] Larsson A, Malm J, Grubb A, Hansson LO. Calculation of glomerular filtration rate expressed in $\mathrm{mL} / \mathrm{min}$ from plasma cystatin C values in $\mathrm{mg} / \mathrm{L}$. Scand J Clin Lab Invest 2004;64:25-30.

[130] Filler G, Lepage N. Should the Schwartz formula for estimation of GFR be replaced by cystatin C formula? Pediatr Nephrol 2003;18:981-5.

[131] Le Bricon T, Thervet É, Froissart M, Benlakehal M, Bousquet B, Legendre C et al. Plasma cystatin $C$ is superior to 24-h creatinine clearance and plasma creatinine for estimation of glomerular filtration rate 3 months after kidney transplantation. Clin Chem 2000;46:1206-7.

[132] Sjostrom P, Tidman M, Jones I. Determination of the production rate and nonrenal clearance of cystatin $C$ and estimation of the glomerular filtration rate from the serum concentration of cystatin C in humans. Scand J Clin Lab Invest 2005;65:111-24.

[133] MacIsaac RJ, Tsalamandris C, Thomas MC, Premaratne E, Panagiotopoulos S, Smith TJ, et al. Estimating glomerular filtration rate in diabetes: a comparison of cystatin-C- and creatinine-based methods. Diabetologia 2006;49:1686-9

[134] Bouvet Y, Bouissou F, Coulais Y, Seronie-Vivien S, Tafani M, Decramer S, et al GFR is better estimated by considering both serum cystatin C and creatinine levels. Pediatr Nephrol 2006;21:1299-306

[135] Zappitelli M, Parvex P, Joseph L, Paradis G, Grey V, Lau S, et al. Derivation and validation of cystatin C-based prediction equations for GFR in children. Am J Kidney Dis 2006;48:221-30.

[136] Ma YC, Zuo L, Chen JH, Luo Q, Yu XQ, Li Y, et al. Improved GFR estimation by combined creatinine and cystatin C measurements. Kidney Int 2007;72: $1535-42$.

[137] Stevens LA, Coresh J, Schmid CH, Feldman HI, Froissart M, Kusek J, et al. Estimating GFR using serum cystatin $C$ alone and in combination with serum creatinine: a pooled analysis of 3,418 individuals with CKD. Am J Kidney Dis 2008;51:395-406.

[138] Schwartz GJ, Schneider MF, Maier PS, Moxey-Mims M, Dharnidharka VR, Warady BA, et al. Improved equations estimating GFR in children with chronic kidney disease using an immunonephelometric determination of cystatin C. Kidney Int 2012;82:445-53.

[139] Inker LA, Schmid CH, Tighiouart H, Eckfeldt JH, Feldman HI, Greene T, et al. Estimating glomerular filtration rate from serum creatinine and cystatin C. N Engl J Med 2012;367:20-9.

[140] Masson I, Maillard N, Tack I, Thibaudin L, Dubourg L, Delanaye P, et al. GFR Estimation Using Standardized Cystatin C in Kidney Transplant Recipients. Am J Kidney Dis 2013;61:279-84.

[141] Anon. KDIGO clinical practice guideline for the care of kidney transplant recipients. Am J Transplant 2009;9(Suppl. 3):S1-55.

[142] Schwartz GJ, Haycock GB, Spitzer A. Plasma creatinine and urea concentration in children: normal values for age and sex. J Pediatr 1976;88:828-30.

[143] Bokenkamp A, Domanetzki M, Zinck R, Schumann G, Brodehl J. Reference values for cystatin C serum concentrations in children. Pediatr Nephrol 1998;12:125-9.

[144] Filler G, Priem F, Lepage N, Sinha P, Vollmer I, Clark H, et al. Beta-trace protein, cystatin C, beta(2)-microglobulin, and creatinine compared for detecting impaired glomerular filtration rates in children. Clin Chem 2002:48:729-36.

[145] Filler G, Pham-Huy A. Cystatin C should be measured in pediatric renal transplant patients! Pediatr Transplant 2002;6:357-60.

[146] Helin I, Axenram M, Grubb A. Serum cystatin C as a determinant of glomerular filtration rate in children. Clin Nephrol 1998;49:221-5.

[147] Pham-Huy A, Leonard M, Lepage N, Halton J, Filler G. Measuring glomerular filtration rate with cystatin $C$ and beta-trace protein in children with spina bifida. J Urol 2003;169:2312-5.

[148] Samyn M, Cheeseman P, Bevis L, Taylor R, Samaroo B, Buxton-Thomas M, et al. Cystatin C, an easy and reliable marker for assessment of renal dysfunction in children with liver disease and after liver transplantation. Liver Transpl 2005;11:344-9.

[149] Filler G, Priem F, Vollmer I, Gellermann J, Jung K. Diagnostic sensitivity of serum cystatin for impaired glomerular filtration rate. Pediatr Nephrol 1999;13:501-5. 
[150] Krieser D, Rosenberg AR, Kainer G, Naidoo D. The relationship between serum creatinine, serum cystatin $C$ and glomerular filtration rate in pediatric renal transplant recipients: a pilot study. Pediatr Transplant 2002;6:392-5.

[151] Martini S, Prevot A, Mosig D, Werner D, van Melle G, Guignard JP. Glomerular filtration rate: measure creatinine and height rather than cystatin $\mathrm{C}$ ! Acta Paediatr 2003;92:1052-7.

[152] Stickle D, Cole B, Hock K, Hruska KA, Scott MG. Correlation of plasma concentrations of cystatin $C$ and creatinine to inulin clearance in a pediatric population. Clin Chem 1998;44:1334-8.

[153] Willems HL, Hilbrands LB, van de Calseyde JF, Monnens LA, Swinkels DW. Is serum cystatin $C$ the marker of choice to predict glomerular filtration rate in paediatric patients? Ann Clin Biochem 2003;40:60-4.

[154] Bacchetta J, Cochat P, Rognant N, Ranchin B, Hadj-Aissa A, Dubourg L. Which creatinine and cystatin C equations can be reliably used in children? Clin J Am Soc Nephrol 2011;6:552-60.

[155] Harman G, Akbari A, Hiremath S, White CA, Ramsay T, Kokolo MB, et al. Accuracy of cystatin C-based estimates of glomerular filtration rate in kidney transplant recipients: a systematic review. Nephrol Dial Transplant 2013;28:741-57.

[156] Delanaye P, Nellessen E, Cavalier E, Depas G, Grosch S, Defraigne JO, et al. Is cystatin $\mathrm{C}$ useful for the detection and the estimation of low glomerular filtration rate in heart transplant patients? Transplantation 2007;83:641-4

[157] Wasen E, Suominen P, Isoaho R, Mattila K, Virtanen A, Kivela SL, et al. Serum cystatin $\mathrm{C}$ as a marker of kidney dysfunction in an elderly population. Clin Chem 2002;48:1138-40

[158] Fliser D, Ritz E. Serum cystatin C concentration as a marker of renal dysfunction in the elderly. Am J Kidney Dis 2001;37:79-83.

[159] O’Riordan SE, Webb MC, Stowe HJ, Simpson DE, Kandarpa M, Coakley AJ, et al. Cystatin $\mathrm{C}$ improves the detection of mild renal dysfunction in older patients. Ann Clin Biochem 2003;40:648-55.

[160] Burkhardt H, Bojarsky G, Gladisch R. Diagnostic efficiency of cystatin C and serum creatinine as markers of reduced glomerular filtration rate in the elderly. Clin Chem Lab Med 2002;40:1135-8.

[161] Matsushita K, van d V, Astor BC, Woodward M, Levey AS, de Jong PE, et al Association of estimated glomerular filtration rate and albuminuria with all-cause and cardiovascular mortality in general population cohorts: a collaborative meta-analysis. Lancet 2010;375:2073-81.

\section{Pour en savoir plus}

Delanaye P, Mariat C. The applicability of eGFR equations to different populations. Nat Rev Nephrol 2013;9:513-22.

Séronie-Vivien S, Delanaye P, Pieroni L, Mariat C, Froissart M, Cristol JP. Cystatin $C$ : point d'étape et perspectives. Ann Biol Clin (Paris) 2008;66:301-23.

Smith HW. The kidney: Structure and function in health and disease. New York,

Oxford University Press Inc, 1951.

Stevens LA, Coresh J, Greene T, Levey AS. Assessing kidney function - Measured and estimated glomerular filtration rate. N Engl J Med 2006;354:2473-83.

Björk J, Grubb A, Sterner G, Nyman U. Revised equations for estimating glomerular filtration rate based on the Lund-Malmö Study cohort. Scand J Clin Lab Invest 2011;71:232-9.

Soares AA, Eyff TF, Campani RB, Ritter L, Weinert LS, Camargo JL, Silveiro SP. Performance of the CKD Epidemiology Collaboration (CKD-EPI) and the Modification of Diet in Renal Disease (MDRD) Study equations in healthy South Brazilians. Am J Kidney Dis 2010;55:1162-3.

Tent H, Waanders F, Krikken JA, Heerspink HJ, Stevens LA, Laverman GD, Navis G. Performance of MDRD study and CKD-EPI equations for long-term follow-up of nondiabetic patients with chronic kidney disease. Nephrol Dial Transplant 2012;27 Suppl 3:iii89-95.

Camargo EG, Soares AA, Detanico AB, Weinert LS, Veronese FV, Gomes EC, Silveiro SP. The Chronic Kidney Disease Epidemiology Collaboration (CKD-EPI) equation is less accurate in patients with Type 2 diabetes when compared with healthy individuals. Diabet Med 2011;28:90-5.

van Deventer HE, George JA, Paiker JE, Becker PJ, Katz IJ. Estimating glomerular filtration rate in black South Africans by use of the modification of diet in renal disease and Cockcroft-Gault equations. Clin Chem 2008;54:1197-202.

\section{Disponible en ligne sur}

\section{ScienceDirect}

